Master Thesis

TVVR 19/5013

\title{
Drying Lakes: A Review On The Health Conditions and Restoration Strategies
}

\section{Anchita}

D. S III

Division of Water Resources Engineering

Department of Building and Environmental Technology Lund University 



\section{Drying Lakes: A Review On The Health Conditions And Restoration Strategies}

By:

ANCHITA

Master Thesis

Division of Water Resources Engineering

Department of Building \& Environmental Technology Lund University

Box 118

22100 Lund, Sweden 
Water Resources Engineering

TVVR-19/5013

ISSN 1101-9824

Lund 2019

www.tvrl.lth.se 


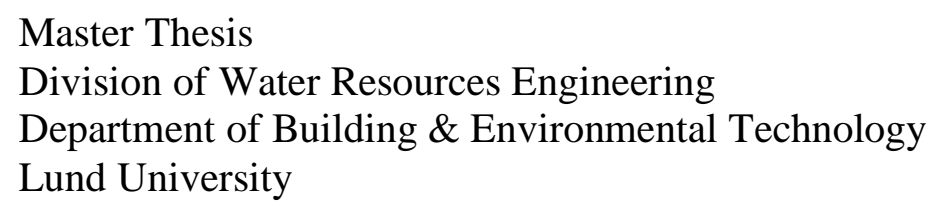

Swedish title:

English title:

Drying Lakes: A Review on The Health Conditions and Restoration Strategies

Author(s):

Anchita

Supervisor

Dr Kamshat Tussupova

Co-Supervisor(s)

Dr Peder Hjorth

Ivan Radelyuk

Examiner:

Rolf Larsson

Language

English

Year:

2019

Keywords:

Drying Lakes; Large Aral Sea; Small Aral Sea; Lake Urmia; Health; Water level; Restoration of Lake; 


\section{Acknowledgements}

I would like to express my deepest gratitude to my supervisor Dr Kamshat Tussupova, Lund University, for her patient guidance and enthusiastic encouragement. It would never be possible without your support and motivation. I would also like to thank my co-supervisors Ivan Radelyuk (PhD student) and Prof. Peder Hjorth, Lund University, for their valuable advice and suggestions. Both supervisor and co-supervisors' doors were always open whenever I ran into trouble or had a question regarding my research or writing. Thanks for steering me in the right direction whenever I needed it. I would also like to thank James Feiccabrino (PhD student), Lund University, for going through my report and helping me identify the necessary changes. I would also like to thank Ehsan Kamali Maskooni, Mojtaba Moravej and Ismael Ahangari for providing me with the necessary data related to Lake Urmia.

I am gratefully indebted to my friend Vivek Udupa for his very valuable comments, helping me improve the figures and tables and for his time going through the data together to complete the report. I will never forget your help thanks for being there for me.

I would like to thank Aron Edwin, Bernard Nsabimana, Pooja Vijay Prakash, Shree Madhu Bhat, Sudhakar Sivakumar and Tendai Hardwork for their involvement and feedback in completing my thesis. I would also like to thank my good friend Jie zhang for her continuous support and encouragement. A special thanks to everyone at the department of water resources engineering for making the environment comfortable.

Finally, I must express my profound gratitude to my parents Nagalaila and Shanmugam and my sibling Harshith for providing me with unfailing support and continuous encouragement throughout my years of study and the process of writing this thesis. Also, I would like to thank my loved ones who have supported me throughout the entire journey. I will be grateful for your love. 


\section{Abstract}

Great salt lakes around the world are drying at a rapid rate. The drying salt lakes give rise to health and socio-economic concerns for the population in the surrounding region. The respective governments undertook various measures to address the concerns relating to the drying of salt lakes. This research aims to assess the strategies towards increasing the water level of saltwater lakes in the case of Lake Urmia and the Aral Sea. Additionally to investigate the health impacts of the decreased water level on the surrounding population in the case of the Aral Sea. A comprehensive case study was conducted on the publications relating to the assessment of health conditions and restoration strategies implemented towards the Aral Sea and Lake Urmia. Research publications and official reports in English and Russian Languages were considered for this research. Based on the studies, it was found that the drying of lakes might not be the cause for the health disorders in the Aral region. The restoration strategy of the salt lakes was found to be a viable option only if sustenance of the restored lake can be promised. 


\section{Table of contents}

Acknowledgements .........................................................................................iii

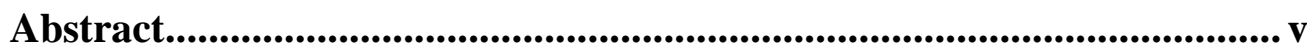

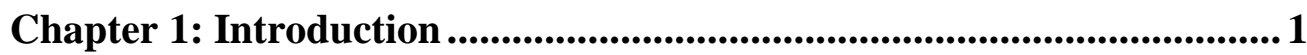

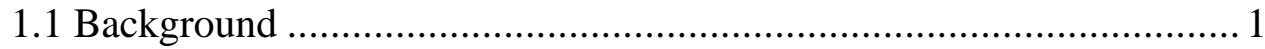

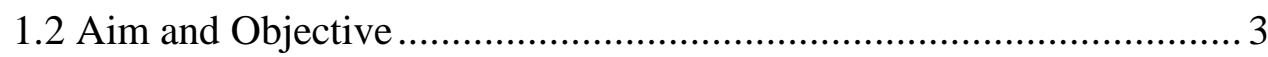

1.3 Description of Lake Drying Process And Its Effects............................ 4

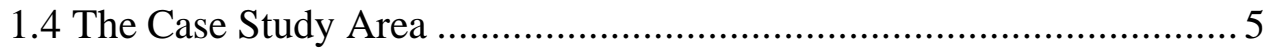

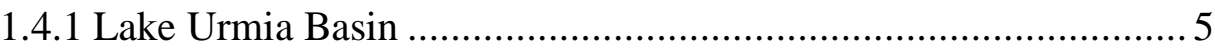

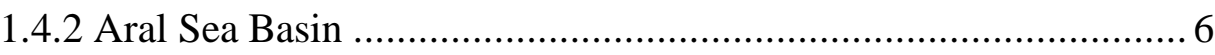

Chapter 2: Methodology ...................................................................................9

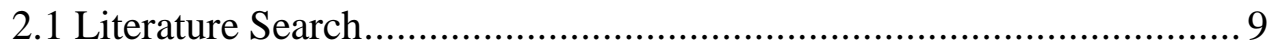

Chapter 3: Drying Salt Lakes and Its Related Health Effects ................. 11

3.1 The Aral Sea And Its Related Health Issues ..................................... 11

3.1.1 Respiratory Disorder ............................................................ 12

3.1.2 Psychological Disorder............................................................. 12

3.1.3 Nervous System Disorder...................................................... 13

3.1.4 Reproductive System Disorder ................................................. 13

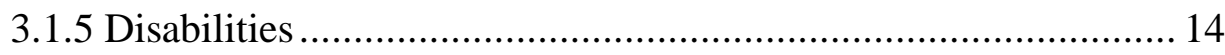

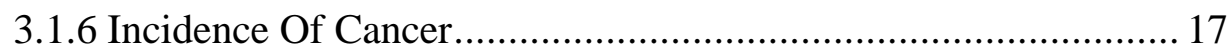

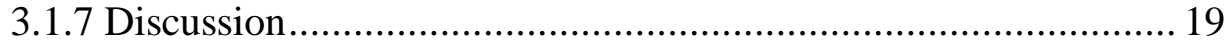

Chapter 4: Restoration of Great Salt Lakes................................................. 25

4.1 Lake Urmia and its Restoration Efforts .......................................... 25

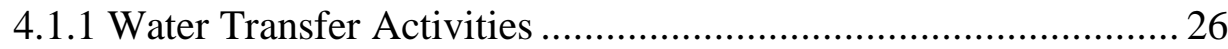

4.1.2 Water Transfer From The Aras River To Lake Urmia................. 29

4.1.3 Water Transfer From The Caspian Sea To Lake Urmia .............. 29

4.1.4 WasteWater transfer from Treatment Plants To Lake Urmia....... 30

4.1.5 Cost Analysis of ULRP ........................................................... 30

4.2 Restoration of the Northern Aral Sea................................................ 31

4.2.1 Syr-Darya Control and Northern Aral Sea Project (SYNAS) ...... 33 
4.3 Restoration of The Southern Aral Sea …........................................... 33

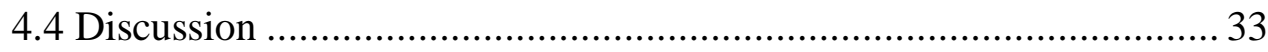

Chapter 5: Discussion......................................................................................... 41

Chapter 6: Conclusion.....................................................................43

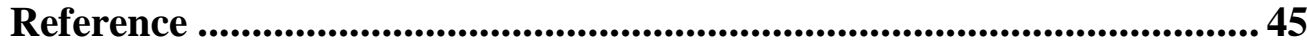

Appendix.................................................................................................................. 53

Appendix A: ULRP activities and related expenses............................... 53

Appendix B: SYNAS activities and related expenses ............................. 55 


\section{Chapter 1: Introduction}

\subsection{Background}

A lake is a water-filled region surrounded by land on all its sides. There are several types of classification for lakes as shown in Figure 1a. The two main types of lakes based on origin are: natural and artificial. Further, lakes can be classified by a) size: ponds and seas (Society, 2011), b) frequency of filling: episodic lakes, intermittent lakes and permanent lakes (Jellison et al., 2008), c) hydro-regime: freshwater lakes and saltwater lakes (Jerome, 2015). Lakes can also be classified by the salinity level of water: Brackish, Saline and Brine (Boros and Kolpakova, 2018; CAWater, 2019; New World Encyclopedia, 2017). All the freshwater lakes are open water bodies with an outlet and saltwater lakes are closed water bodies with no outlet (New World Encyclopedia, 2017).

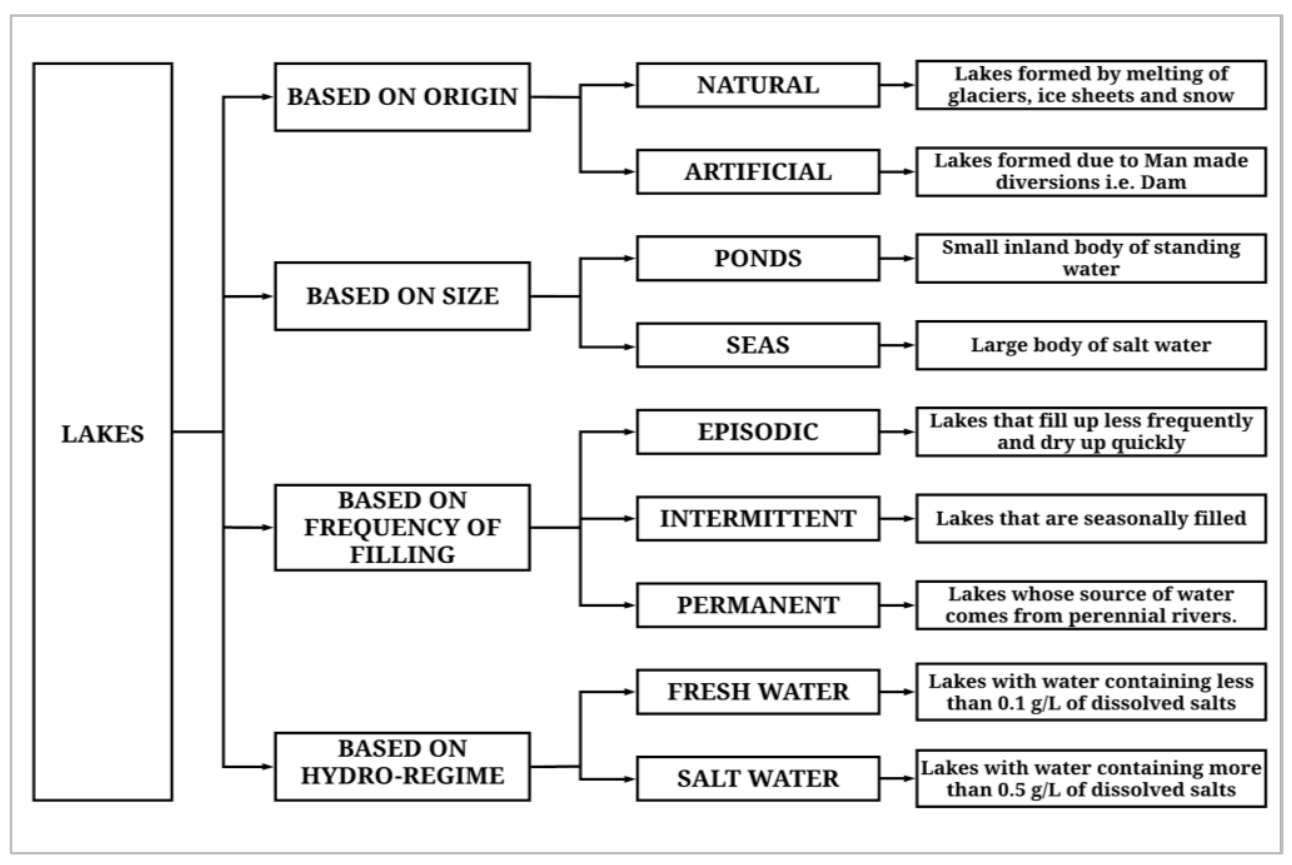

Figure 1a: Classification of Lakes 


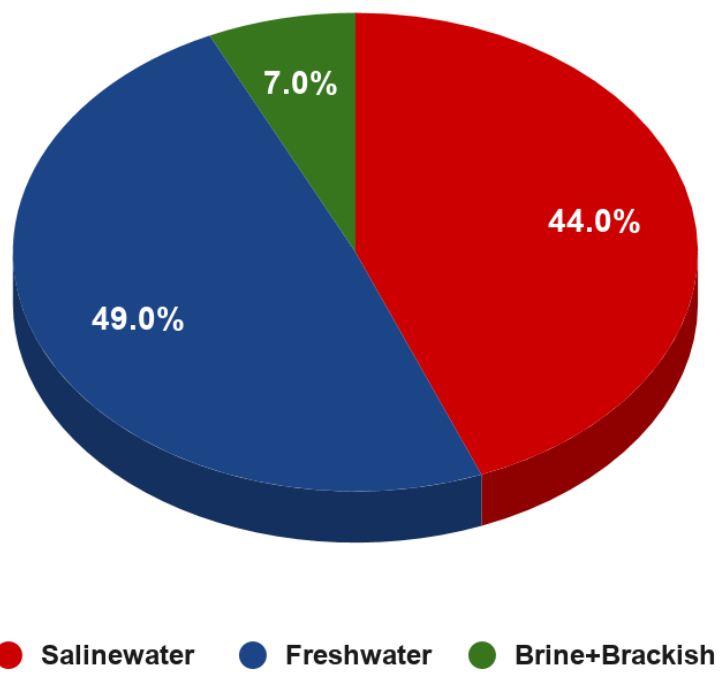

Figure 1b: Distribution of Lakes based on hydro-regime

Saline lakes are endorheic lakes representing $44 \%$ by volume and $23 \%$ by area among all the lakes on earth (Wurtsbaugh et al., 2017) as shown in Figure 1b. Saline lakes are generally confined to arid and semi-arid regions in various countries (Jellison et al., 2008). Seasonally and over time salt concentrations in these lakes fluctuate (Zohary and Ostrovsky, 2011). Precipitation is directly proportional to the lake level. This is a feature of the region and form of lake's basin. Meanwhile, if evaporation increases, the salinity of the lake can increase from 0 to above 50 parts per thousand (ppt) (New World Encyclopedia, 2017; Society, 2011). Some of the world's largest lakes are shown in Figure 2. Among these, the Aral Sea, the Caspian Sea and Lake Urmia have areas greater than 5,000 km2 (Scheffers and Kelletat, 2016). 


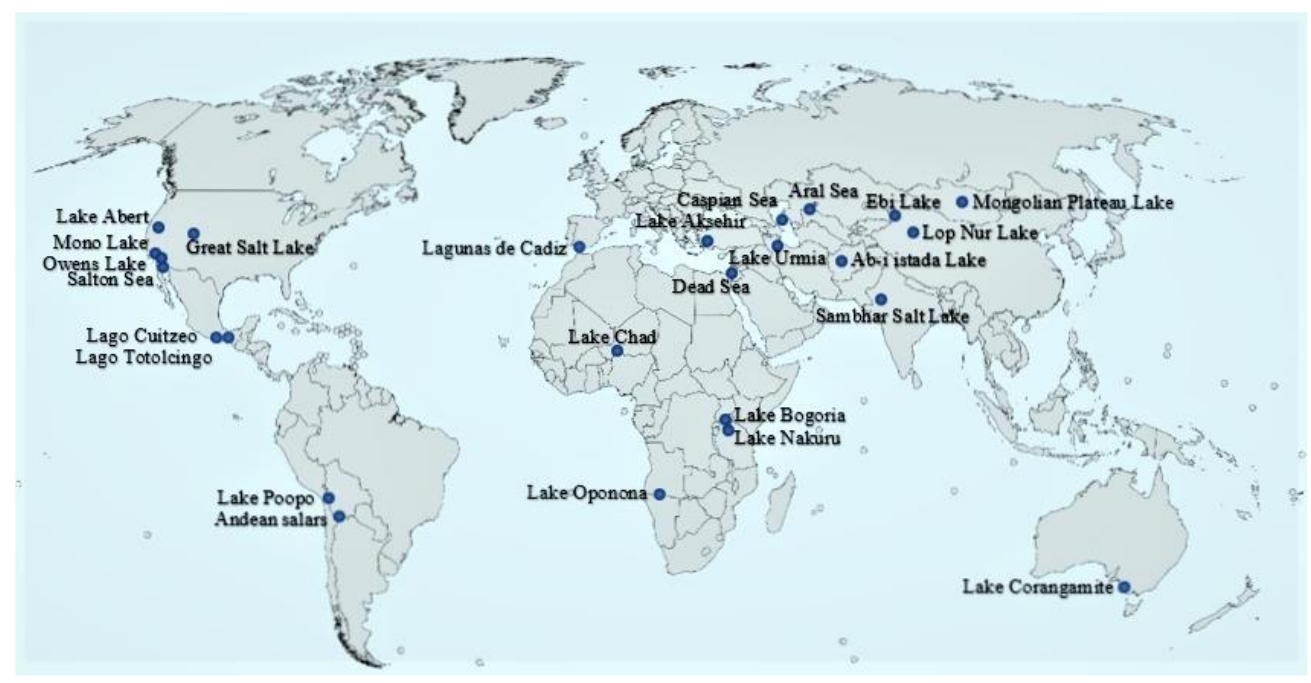

Figure 2: Geographical representation of prominent salt lakes around the world. [Source: Referred from (Wurtsbaugh et al., 2017)]

Once a lake has formed, it does not remain the same. Lakes go through various stages of life like people - young, mature, old, and death. A lake's natural ageing occurs very slowly over hundreds or even thousands of years. This natural process can speed up, spanning over a few decades with human impact also termed as anthropogenic activities (Society, 2011).

Due to anthropogenic activities and induced climatic changes, many lakes in different parts of the world dry up rapidly. Drying of a lake causes problems and those of saline lakes foster the worst. The reduction in the water-filled area of a saline lake forms a salt crust on the dry exposed former bottom of the lake. These salt-crusts are rich in various minerals like sodium chloride, magnesium, calcium, sulphates, borate, lithium and potassium (Jellison et al., 2008). Sand and dust storms usually occur when strong winds lift large amounts of sand and dust from bare, dry soils into the atmosphere (WMO, 2017). There are claims of several health effects due to these dust storms.

As a solution to drying of the salt lakes, policymakers try to design strategies to restore the lake level. This research aims to assess the health effects and efforts made by governments to save drying saltwater lakes based on the case studies of the Aral Sea and Lake Urmia.

\subsection{Aim and Objective}

The aim of the work is to assess the strategies towards increasing the water level of saltwater lakes in case of Lake Urmia and the Aral Sea. Additionally, 
in the case of Aral Sea, the health impact of the decreased water level on the surrounding population is investigated.

An extensive review of the published case studies on the health conditions and the restoration expenses of the Aral Sea and Lake Urmia was performed. The Aral Sea and Lake Urmia are among the fastest drying saltwater lakes observed in the past 50 years (Newton, 2018). These two lakes are saline by nature and have reduced by $90 \%$ of their former area over the last 40-50 years (Fazel et al., 2018; Harriman, 2015). The Aral Sea had more health-related case studies as compared to other Lakes. Thus, the Aral Sea was chosen for health impact assessment. The following condition of the lakes provided a good opportunity for perspective assessment.

Northern Aral Sea, Kazakhstan - A successfully restored lake

Lake Urmia, Iran - A lake amidst the restoration process

Southern Aral Sea, Uzbekistan - A lake where the efforts to restore were ceased.

Considering all the three perspectives will allow for a comparative discussion on the worth of restoring a drying saltwater lake.

\subsection{Description of Lake Drying Process And Its Effects}

Salt lakes are endorheic in nature. Rivers, groundwater and precipitation recharge the lakes and since the salt lakes are endorheic, evaporation is the only means of outflow. A lake's water level is said to be self-sustaining when the inflow and outflow are in balance. As observed in the past 50-60 years, the water inflow to several great salt lakes, like the Owens Lake, Lake Urmia, Aral Sea and the Great Salt Lake in Utah have been low, breaking the balance and resulting in the reduction of each lake's water level (Wurtsbaugh et al., 2017).

Anthropogenic activities contribute greatly to the fluctuation of a lake's water level. According to studies (Wurtsbaugh et al., 2017) conducted in the late 19th century and the early 20th century, many lakes including the ones mentioned above were characterized as having water level fluctuation. The enormous amount of water diverted from rivers for urbanization, industrial and agricultural uses resulted in the reduction of water level.

The water level and salinity are inversely related to each other. A decrease in the water level causes an increase in water salinity. The biodiversity in salt lakes is affected by the higher level of salinity. A reduction of the water level also reduces the water-covered areas exposing the dry salt-rich bottom of a lake to the atmosphere. Dust storms carry these salts from dry lake beds and spread it around nearby regions. 
The population living in the vicinity of these drying lakes are faced with several health disorders. It is widely believed that the drying of saltwater lakes causes health disorders (Heydari and Jabbari, 2012; Wiggs et al., 2003; Wurtsbaugh et al., 2016). In order to determine the relationship between the drying of the salt lakes and the prevailing health issues, this research considers the case studies of the Aral Sea region. Numerous studies regarding the health of the population living in the Aral Sea region have been conducted in the past making it an ideal case study for health condition assessment.

\subsection{The Case Study Area}

\subsubsection{Lake Urmia Basin}

Lake Urmia in Northeast Iran ( $\left.37^{\circ} 41^{\prime} 59.99^{\prime \prime} \mathrm{N}, 45^{\circ} 18^{\prime} 60^{\prime \prime} \mathrm{E}\right)$ is one of the largest salt lakes in the world and it is recognized as a biosphere reserve by UNESCO. It is also a national park under the 1971 Ramsar Convention (Khatami and Berndtsson, 2013). The lake basin is shared between the five provinces of East Azerbaijan (38.9\%), West Azerbaijan (41.8 \%), Kurdistan $(10.2 \%)$, Ardebil $(0.1 \%)$, and Zanjan $(0.04 \%)$ as shown in Figure 3. The Ardebil and Zanjan shares of the Lake Urmia basin have no population. The share of the population of East Azerbaijan, West Azerbaijan, and Kurdistan provinces is $54.3 \%, 41.4 \%$, and $4.3 \%$, respectively (ULRP, 2015a). Lake Urmia occupied an area of 5,200 $\mathrm{km}^{2}$ and was $140 \mathrm{~km}$ long, $55 \mathrm{~km}$ wide and $16 \mathrm{~m}$ deep with high brine water. Lake Urmia has been shrinking for almost 20 years and currently, it is reduced by $90 \%$ of its original size (ULRP, 2015b). 


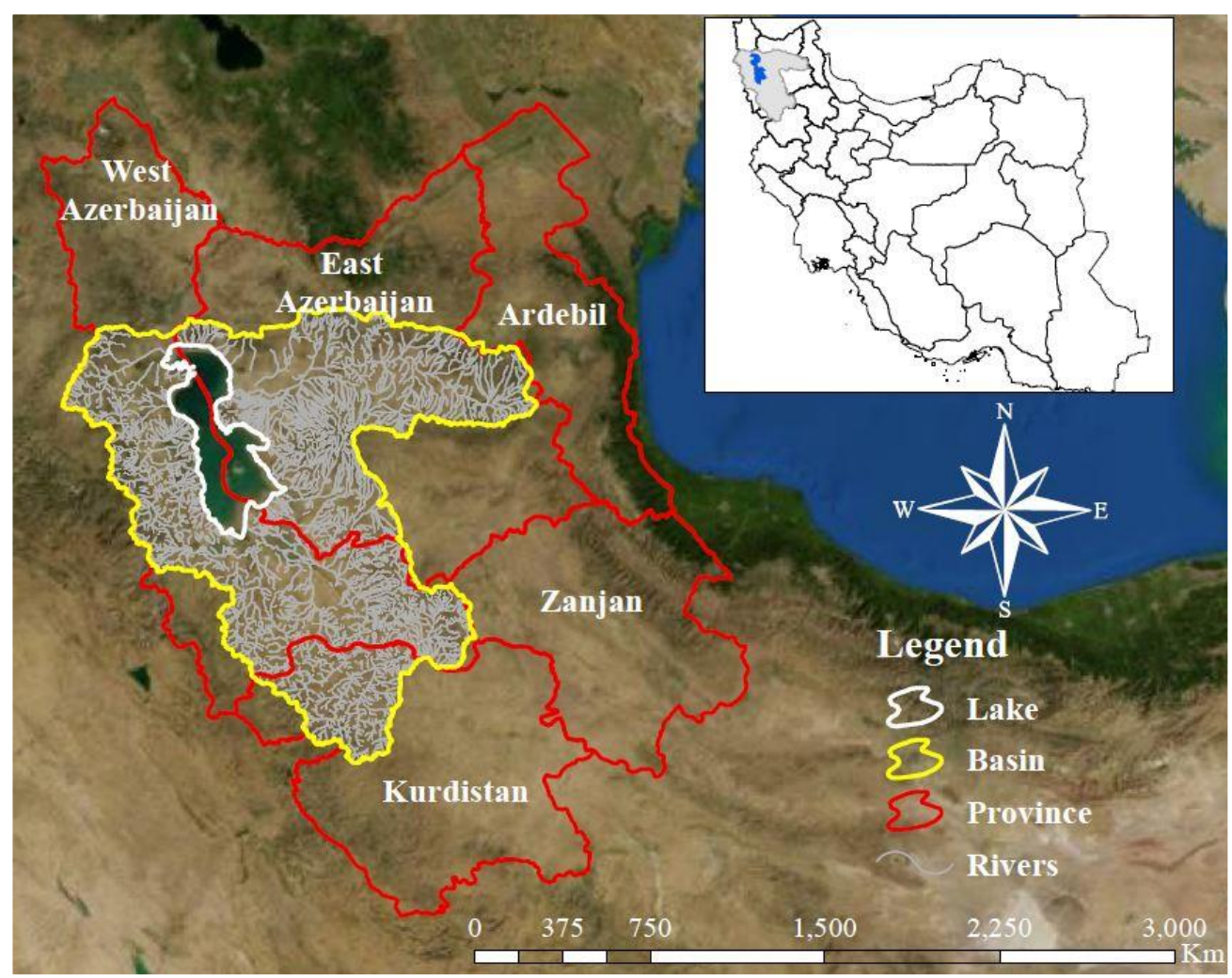

Figure 3: Geographical representation of Lake Urmia Basin

\subsubsection{Aral Sea Basin}

The Aral Sea Basin (ASB) which encompasses the Aral Sea, is shared between five countries namely: Kazakhstan, Kyrgyzstan, Tajikistan, Turkmenistan and Uzbekistan. ASB was mainly fed by two main tributaries: the Amu Darya from the North and Syr Darya from the East as shown in Figure 4 (Micklin, 2019).

The Aral Sea was once the fourth largest lake in the world and the largest saline endorheic drainage basin in Central Asia. The total area of the Aral Sea in 1960 was $68,478 \mathrm{~km}^{2}$ and with a water capacity of $1093 \mathrm{~km}^{3}$. Since then it has drastically reduced due to diminishing water inflow (CAWater, 2019). The water level decreased from $53.40 \mathrm{~m}$ to $41.02 \mathrm{~m}$ during the period $1960-1986$ (CAWater, 2019). In 1986, the Kokaral desert was formed which separated the Aral Sea into the North Aral Sea (NAS) and South Aral Sea (SAS) (Breckle and Geldyeva, 2012). 


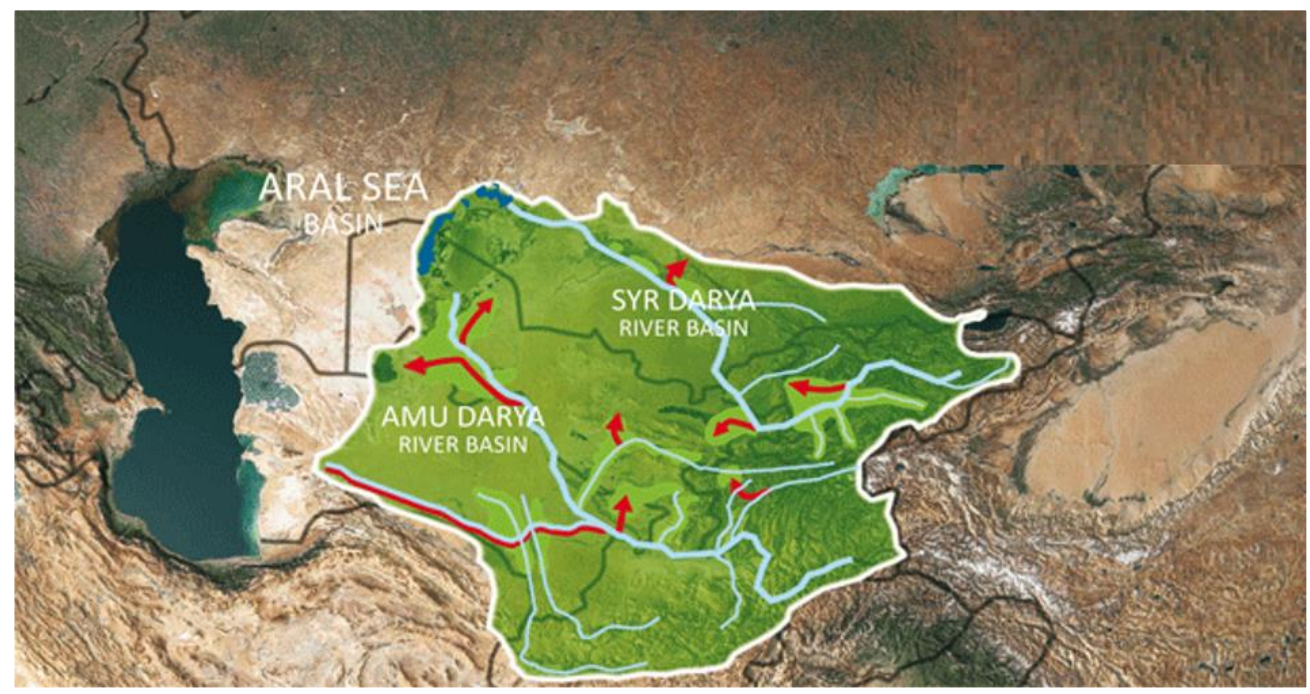

Figure 4: Geographical representation of the Aral Sea Basin. Light blue lines: short lines indicate Amu Darya and Syr Darya tributaries and Long thick lines indicate tributaries of Aral Sea. Dark blue indicates Aral Sea. Red lines indicate the water withdrawal through irrigation canals from tributaries. Light green indicates Irrigated lands. [Source: Modified from (IFAS, 2011)]

The North Aral Sea belonging to Kazakhstan $\left(46^{\circ} 48^{\prime} \mathrm{N}, 61^{\circ} 40^{\prime} \mathrm{E}\right)$ had a surface area of $5,992 \mathrm{~km}^{2}$, with a water volume of $80 \mathrm{~km}^{3}$, maximum depth of $29 \mathrm{~m}$ with an average depth of $13.3 \mathrm{~m}$. NAS is fed by the Syr Darya tributary which is the confluence of Naryn and Kara-Darya rivers in the Feraghan valley. It is the second-longest river in Central Asia and reaches NAS after travelling 2,212 km through the Feraghan valley. Along this course, Syr Darya receives water from 7 rivers namely the Ohangaron and Chirchiq in Uzbekistan and the Arys, Badam, Boroldai, Bungun and keles in Kazakhstan (Micklin, 2019).

South Aral Sea belongs to Uzbekistan $\left(45^{\circ} 00^{\prime} \mathrm{N}, 60^{\circ} 00^{\prime} \mathrm{E}\right)$ and had a surface area of $60,000 \mathrm{~km}^{2}$, with a water volume of $984 \mathrm{~km}^{3}$. SAS is fed by the Amu Darya tributary which is the confluence of the Pyanj and Vaksh rivers. It is the largest river in Central Asia which travels 2,550 km from the place of confluence to get discharged into SAS. Along this course, Amu Darya receives water from 4 rivers namely Kunduz (Afghanistan), Kafirnigan (Tajikistan), Sherabad (Uzbekistan) and Surkhandarya (Uzbekistan). SAS was further split into East and West Aral Seas with surface area $46,466 \mathrm{~km}^{2}$ and $302.8 \mathrm{~km}^{2}$ respectively. However the East Aral Sea was shallow with a max depth of 28 $\mathrm{m}$ and an average depth of $14.7 \mathrm{~m}$ and the West Aral Sea was deeper with a max depth of $69 \mathrm{~m}$ and the average depth of $22.2 \mathrm{~m}$ (Micklin, 2019). 


\section{Chapter 2: Methodology}

\subsection{Literature Search}

The primary research strategy used for this master's thesis was a literature review. A thorough review of what has already been published on the subject was performed.

Online open-source materials and other materials with permission were used for the literature review in this thesis. This includes results from search engines like Google Scholar, LUBearch, PubMed, ResearchGate, ScienceDirect, Scopus, Springer, and Tandfonline. The reports by WorldBank and databases from the Food and Agriculture Organization (FAO) and Central Asia Water (CAWater) were also considered. Relevant official government records, magazines and newspaper articles were also considered for this study. It is to be noted that the data is restricted to scientific publications in Russian and English languages only. Keywords used to scout the information for the review were: "Aral Sea and health issues", "Restoration of lake", "Health in Kazakhstan", "Health in Uzbekistan", "Aral Sea Health", "Aral Sea Kazakhstan", "Aral Sea Uzbekistan", "Urmia lake restoration program", "Drying of a lake", "Aral Sea". 


\section{Chapter 3: Drying Salt Lakes and Its Related Health Effects}

Salt lakes around the world are drying at an alarming rate. Diminishing wet area exposes the dry bottom to the atmosphere. The lake forms a salt crust on the dry exposed lake bed. These salt-crusts are rich in various minerals like sodium chloride, magnesium, calcium, sulphates and potassium. These minerals are profitable in certain cases. Minerals from Lake Munclin (Sahara desert) and the Dead Sea act as fertilizer, salts from Lake Minchin (Salar de Uyuni salt pan) in Bolivia, is extracted for table salt and lithium, salt from Bristol Lake in California is extracted for industry and food products (Deocampo and F Jones, 2014; LUDB, 2019), and salt from the dry lake bed of Lake Zuni are harvested for medicines (Pezzullo and Cox, 2017; Sacred Land Film Project, 2003; Scurlock, 1998). However, exposed lake beds can also create a public health hazard. They become the source for fine sediments, which is picked up by the dust storms and spread across long distances presumably causing an increase in Respiratory problems (asthma attacks), lung diseases and related infections. To better understand the health hazards, this chapter explores studies conducted on the health issues surrounding the Aral Sea.

\subsection{The Aral Sea And Its Related Health Issues}

The Aral Sea Basin (ASB) was shared by several countries for hydropower and irrigation. There was an increase in cotton irrigation during the 1980s which attracted the population to migrate to the ASB from other parts of the Soviet Union (Water Unites, 2019).

The population in Central Asia rose (1897-1959) from 10.5 million to 24.7 million (Islamov, n.d.). This increase in population demanded more agricultural products for sustenance. Therefore, a large amount of water was abstracted from the Aral Basin for irrigation. The increase in water withdrawal from two rivers, the Amu Darya and the Syr Darya for industrial, agricultural and domestic use, limited water flow into the Aral Sea. This facilitated the shrinking of the Aral Sea. Moreover, the return flow was contaminated with industrial and agricultural wastewater. Wastewater contributed to the increase in salinity of the Aral Sea. In 1986, the Aral Sea was divided into two parts, the North Aral and South Aral Sea affecting the inhabitants of two riparian countries: Kazakhstan and Uzbekistan. 
In 1988, the population living in Aral Sea region of Uzbekistan and Kazakhstan was 4 million (Columbia, 2019; Peachey, n.d.). The exposed bottom of the sea had a dry salt crust which contained numerous pollutants. The dry land turned to desert called Aralkum. This desert has been experiencing strong winds which could be termed as dust storms (Opp et al., 2019). These dust storms carry the contaminated salts and deposit them on land and domestic water sources, reportedly causing several health issues like respiratory disorder, disability, reproductive system disorders and tumours to the people living in the Aral Sea region.

Numerous studies conducted by scientists show that the state of the health of the population in the Aral Sea region has continued to deteriorate in recent decades (Masnaveva et al., 2012). In 1991, researchers found a high incidence of cardiovascular diseases, disorders of lipid metabolism and a high frequency of hypertension due to pesticides (Rsymendiev, 1991). The following sections of this report contain details about the health conditions of the population in the Aral Sea region.

\subsubsection{Respiratory Disorder}

The spread of atmospheric air pollutants caused by dust storms has led to respiratory diseases such as chronic bronchitis, bronchial asthma, and tuberculosis. An annual analysis of asthmatic status in Central Asia found that about 113 per 100,000 people suffered from asthma in the Khorezm region of Uzbekistan. This is more than 3 times higher than the national average (38 incidences per 100,000 of the population). In Karakalpakstan, asthma was diagnosed in 67 per 100,000 people which is 2 times more than the national average (Sakiev, 2016). Researchers Kunii et al. 2003 and Bennion et al. 2007, conducted studies in Uzbekistan during the year 2000 to find the connection between the dust storms and respiratory disorders among the children residing near the Aral Sea. These studies considered subjects from $200 \mathrm{~km}$ and $500 \mathrm{~km}$ from the Aral Sea to compare the lung functionalities and other respiratory disorders such as wheezing, coughing and asthma. These studies conclude that there may be no connection between dust storms and respiratory disorders.

\subsubsection{Psychological Disorder}

Psychological disorders refer to a wide range of conditions which affect the mood, thinking and behaviour of an individual. A number of cognitive disorders were found in the population of the Aral Sea region, for instance, different psycho-emotional disorders, depression and decrease in short-term memory, long-term memory and attention span were observed. 
During May 1999, a study (Crighton et al., 2003) was conducted to determine the connection between the drying of the Aral Sea and the mental health of the population surrounding it. The study involved interviewing 118 randomly selected individuals in Karakalpakstan. The survey included a general health questionnaire, Somatic Symptom CheckList-90 (SCL-90, which is psychometric self-report designed to evaluate a broad range of psychological problems) and questions about the perception of the environmental disaster and social support. About $41 \%$ of participants reported concerns regarding environmental issues and $48 \%$ reported stages of somatic symptoms connected with mental distress which was above the standardized cut point (0.36); Cutpoint refers to a mean score above the population norm signifying a probable case of emotional distress manifested as somatic symptoms (0.36(Derogatis et al., 1973)).

Another study (Sakiev, 2016) compared the available clinical records of the Aral and the Kyzyl-Orda in Kazakhstan to understand the mental and behavioural conditions of the population inhabiting the above-mentioned regions. It was reported that the Aral region had about 1.4 times more occurrence of psychological disorder (642.9 cases per 1000 population) than in the Kyzyl-Orda region in Kazakhstan (451.5 cases per 1000 population).

\subsubsection{Nervous System Disorder}

The adverse effect of environmental factors is indicated by an increase in disorders of the central nervous system like mental disorders and decreased intelligence (Gordeev et al., 2013). Highly toxic substances such as lead, nickel and chromium cause asthenia and psychogenic disorders (Sakiev, 2016). The prevalence of depressive personality disorders in the Aral region exceeds that of the Kyzyl-Orda region by almost 3 times, the prevalence of anxiety disorders by 2.5 times and depressive disorders by more than 2 times.

Nervous system disorders are found to be at a relatively very high rate in the Aral region. Almost one in ten of the women surveyed in Kazalinsky district of Kazakhstan and Yany-Kurgan district of Uzbekistan within the Aral region suffered from diseases of the nervous system, and the peak of the frequency of these diseases falls between the age of 20-50 years (Aubakirova et al., 2015; Iznak et al., 2011; Kamchatnov, 2014; Sakiev, 2016; Zotkina et al., 2013).

\subsubsection{Reproductive System Disorder}

In the Aral district, it was found that among the demographic indicators, there was a decrease in life expectancy along with a high perinatal and infant mortality (Alnazarova, 2010). Out of the 19,561 mortality cases between 19992008 in the Kyzylorda district, 16.1\% (3155) were women of reproductive age 
(15-49 years) (Tereshkevich et al., 2011). The average annual mortality rate for women in the Kyzylorda district in the fertile age range was $1.98 \pm 0.05$ per 1000 population, which tended to decrease in the dynamics for 1999-2008 by $2.15 \%$. High mortality rates of $4.51 \pm 0.17$ per 1000 population were established in the late reproductive age 45-49 years old (Tereshkevich et al., 2011). According to the survey performed on women's reproductive health in Kazakhstan, the women in the Aral district when compared to other parts of the Soviet region were facing later menarche, menstrual disorders and spontaneous miscarriages. At the same time, a positive trend in reproductive behaviour was observed. The optimal reproductive age is between 20 to 34 years of age among $88.2 \%$ of the labouring population of women. The usage of contraceptives was quite high for the region (Intrauterine Device in 32.1\%) and the frequency of abortions was low (5.5\%) (Bochkov, 2003; Kuzmin, 2005; Reilly, 2001; Sakiev, 2016; Wunsh, 2007).

The onset of pregnancy in most women residing in Aral district occurs against a background of irregularities in the hematopoietic, pituitary-thyroid, and immune systems. During pregnancy, women were affected by the improper intake of nutrition. Meanwhile, the immune system of babies is threatened by lack of breastfeeding avoided due to medical concerns caused by long term exposure of pesticides in the Aral Sea region (Bochkov, 2003; Kuzmin, 2005; Reilly, 2001; Sakiev, 2016; Wunsh, 2007). Such compounds accumulate in fetuses through placenta and breastfeeding in the postnatal period. Hence, we can say that negative environmental factors and toxicants have a huge impact on women's reproductive health (Sakiev, 2016; Turdybekova et al., 2017).

\subsubsection{Disabilities}

According to a study conducted by researcher Sakiev, disability of the population may increase in Aralsk, Kazalinsk, Shalkar, Karmakshy, Zhalagash, Arys, Irgiz and Ulytau districts. Stability in health condition among the population was observed in the Zhanaarka district as shown in Figure 5.

The Kazakhstan law (Sakiev, 2016) divided the study area into 3 zones: Catastrophe zone (Aralsk, Kazalinsk, Shalkar) which was within 0-250 km from the Aral Sea, the Crisis zone (Karmakshy, Zhalagash) which was within 250-370 km from the sea and the Pre-Crisis zone (Arys, Irgiz and Ulytau) which is $370-810 \mathrm{~km}$ from the sea. These zones were compared to a control region (Zhanaarka) which was beyond $811 \mathrm{~km}$ from the sea. 


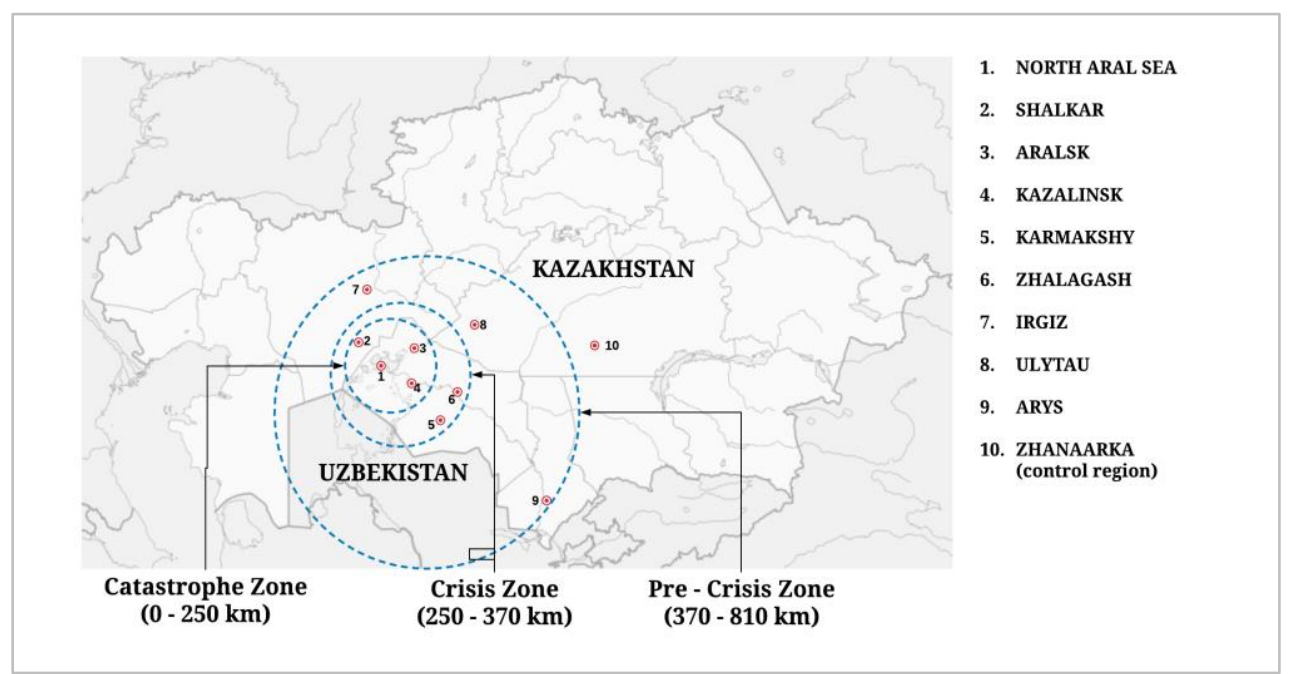

Figure 5: Study area for disabilities in the Aral region of South Kazakhstan

The Analysis of the results (Comprehensive Approaches To The Management Of The Health Condition Of Population Of The Areal Region) for the study period 2004-2013 revealed the prevalence of 6 classes of pathology: cardiovascular diseases were perhaps highest, respiratory diseases were the 2nd highest, vision pathologies were the 3rd and mental disorders were the 4th, Malignant Neoplasms were the 5th and injuries were the least. The disability rate in 3 zones as compared to the control region is shown in Figure 6 (Sakiev, 2016).

The incidence rate is a measure of the frequency with which a disease or other incident occurs over a specified time period (Hargrave, 2019). The health of the population residing in the 4 above-mentioned zones was observed from $2004-2013$ and the incidence rate of the selected diseases were calculated per 10,000 population.

Figure 6 shows that the incidence rates of Respiratory disabilities were highest in the catastrophe zone, while cardiovascular and psychological disabilities were peaking in the crisis zone.

The study also displays a calculation of predicted disability occurrence for the year 2023 based on the disabilities observed from 2004 up to 2013. The prediction was based on the 10 year average of incidence of disabilities (from 2004 up to 2013) and the recorded disabilities at the end of the study year, 2013. 


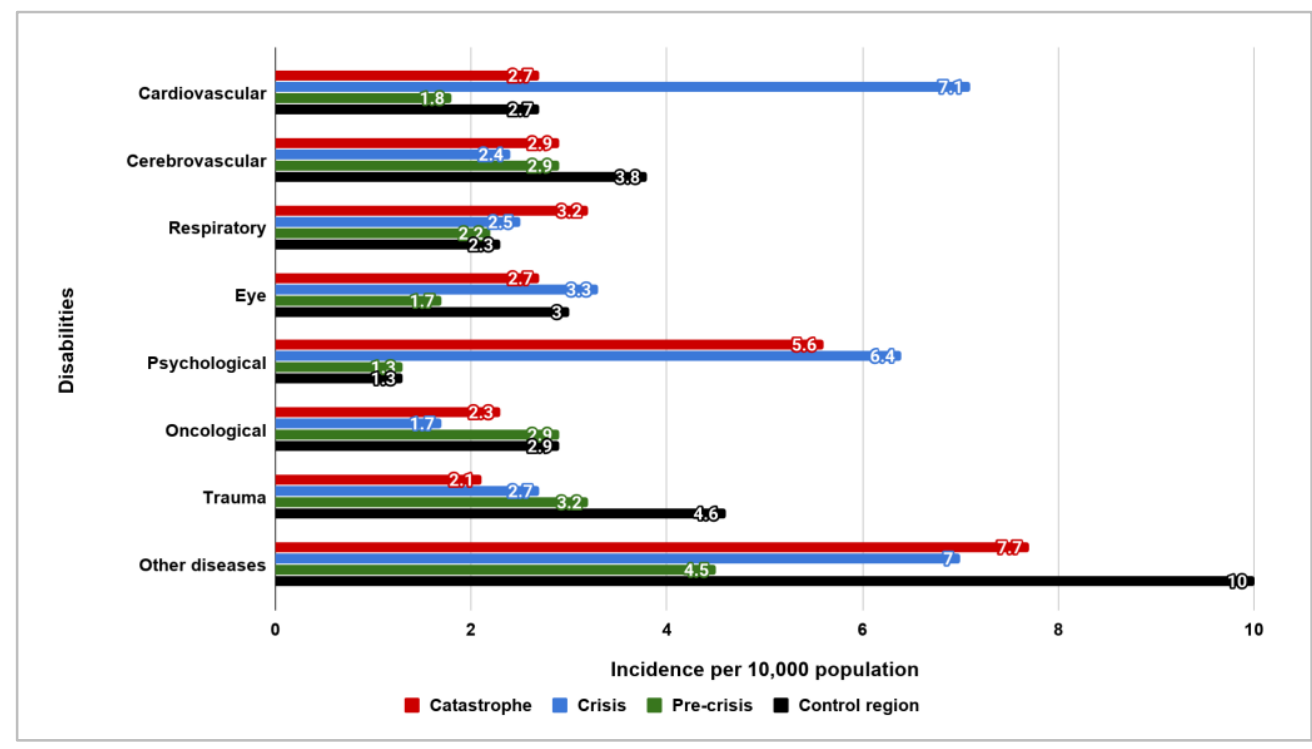

Figure 6: The structure of the primary disability of adults per 10,000 of the population in the Aral Sea region for the years 2004-2013. [Source: data extracted from (Sakiev, 2016)]

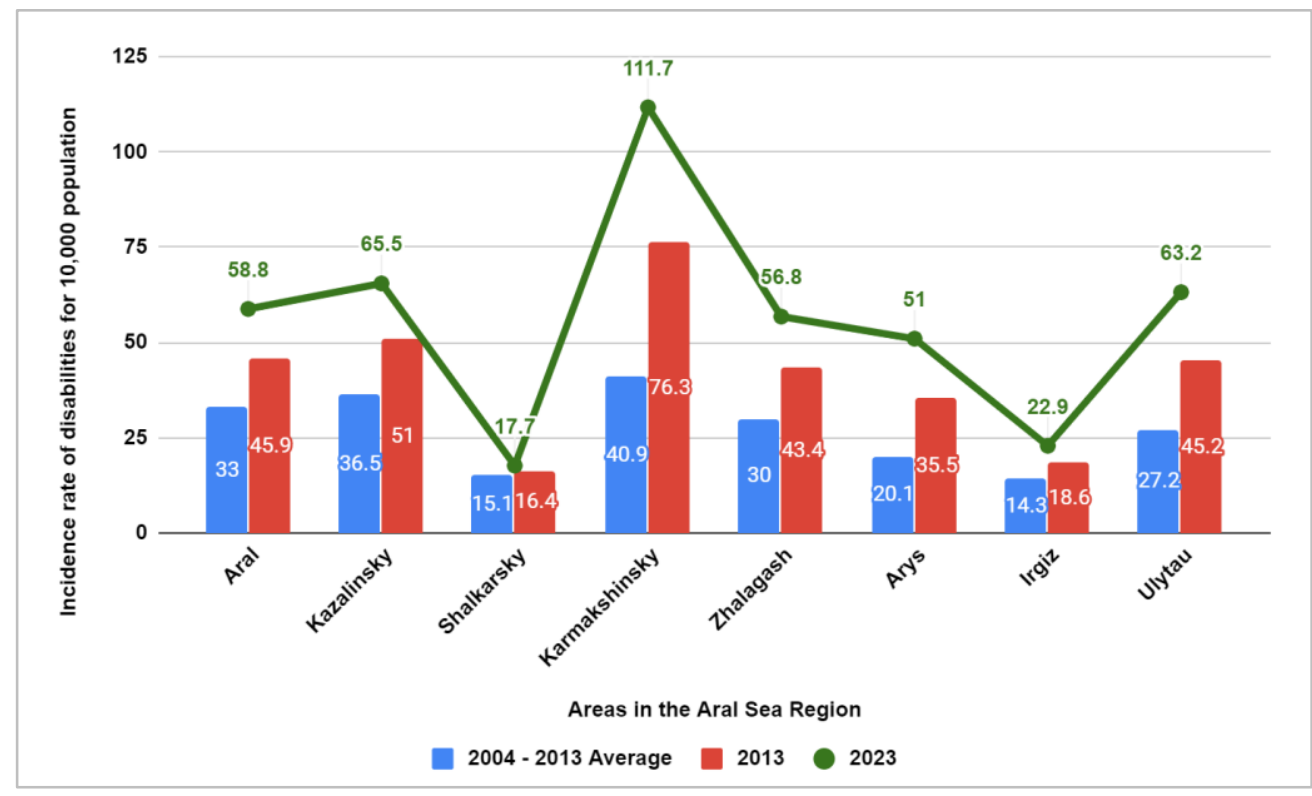

Figure 7: Predicted incidence of disabilities based on recorded disabilities during the period 2004 - 2013. [Source: data extracted from (Sakiev, 2016)]

The predicted incidence of disability for the year 2023 as shown in Figure 7, reveals a $28.1 \%$ increase in the Aralsk district, $28.4 \%$ increase in the Kazalinsk district, a $7.9 \%$ increase in the Shalkar district, $46.4 \%$ increase in the 
Karmakshy district, $30.9 \%$ increase in Zhalagash district, $43.7 \%$ increase in Arys district, $23.1 \%$ in Irgyz and $39.1 \%$ increase in the Ulytau district. This shows an overall trend of increasing disabilities expected between 2013 and 2023 in the Aral Sea region.

\subsubsection{Incidence Of Cancer}

Malignant neoplasm (a cancerous tumour) is another health disaster to be considered while analyzing the health effects in the Aral Sea region. For the analysis of the incidence of malignant neoplasm, the data from a 10 year (2004 - 2013) timeframe was considered. The data was reported to be taken from local oncology dispensaries. Figure $8 \mathrm{a}$ shows the 10 year average Malignant neoplasm incidence in the three disaster zones (catastrophe, crisis and precrisis as described in Figure 5), Zhanaarka district and the whole of the Republic of Kazakhstan for comparison purposes. The incidence rates were calculated for a population of 100,000 residing in the above-mentioned areas.

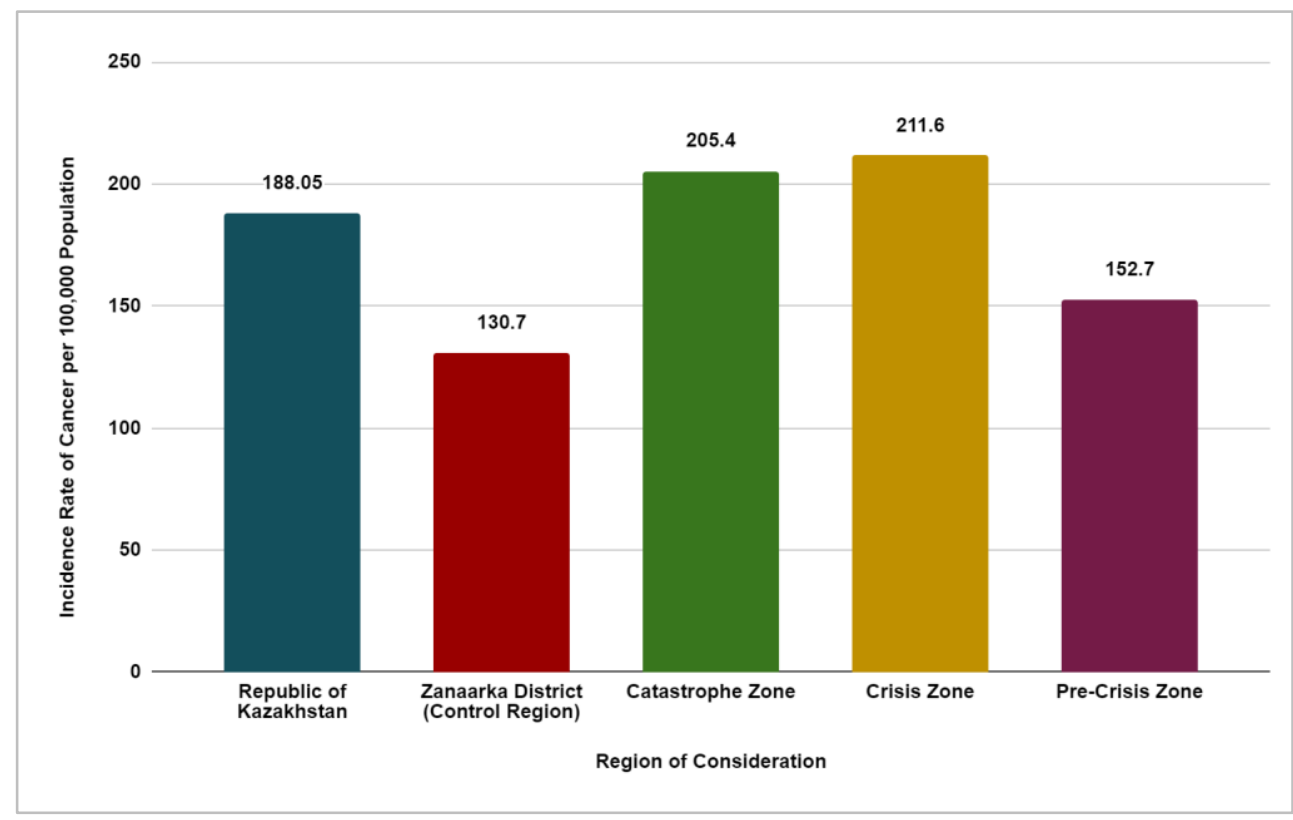

Figure 8a: 10 year Annual Average of Cancer Incidence Rates 100,000 people for the period 2003 - 2014. [Source: data extracted from (Mamyrbayev et al., 2016)]

The catastrophe and the crisis zones have 57.2\% (211.6) and 61.9\% (205.4) increased the incidence rate of Malignant neoplasm respectively when compared to the control region (130.7). The incidence rate in the pre-crisis region is 152.7 for 100,000 population which is $16.8 \%$ higher when compared to the control region but is $18.8 \%$ lower as compared to the Republic of 
Kazakhstan. Figure $8 \mathrm{~b}$ elaborates the observations made at locations belonging to the three crisis zones. The two horizontal lines work as reference points, representing the cancer incidence rates at the Republic of Kazakhstan and in the control region, Zhanaarka.

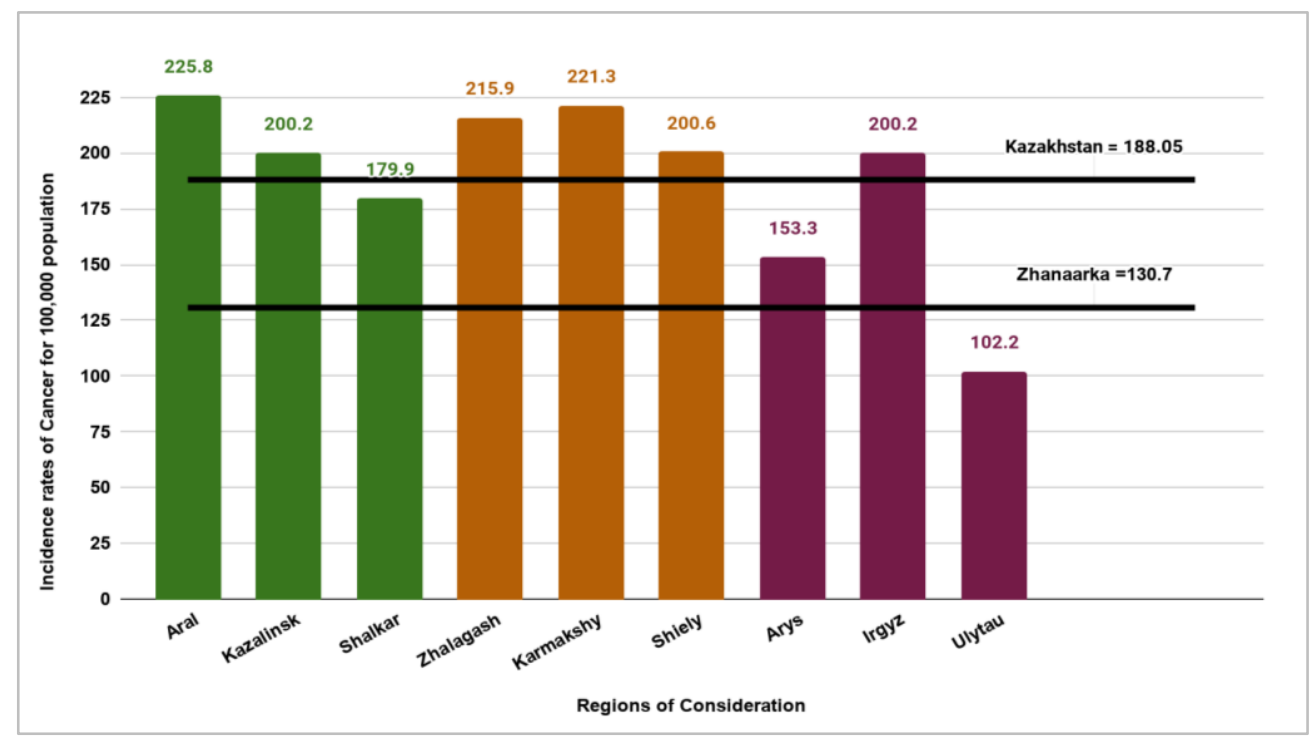

Figure 8b: 10 year Annual Average of Cancer Incidence in the Aral Sea regions recorded during the year 2003-2014. [Source: data extracted from (Mamyrbayev et al., 2016)]

The incidence of Cancer in the catastrophe zone was notably higher than in the control region as discussed previously. The three districts belonging to the catastrophe zone are Aral, Kazalinsk and Shalkar. The malignant neoplasm incidents observed in the Aral region was 225.8 per 100,000 population, in Kazalinsk was 200.2 per 100,000 population and in Shalkar it was 179.9 per 100,000 population. These observations are $1.7,1.5$ and 1.4 times greater respectively compared to the control region, Zhanaarka (130.7 per 100,000 population).

Similarly, the observations made at the crisis zone which includes Zhalagash, Karmakshy and Shieli are higher than the control region and the Republic of Kazakhstan. The incidence rates observed in the Zhalagash 215.9, Karmakshy 221.3 and Shieli regions 200.6 were each calculated per 100,000 population. These observations were $1.65,1.69$ and 1.53 times greater than the control region.

For the pre-crisis zone which is made up of Arys, Irgiz and Ulytau, the observed cancer incidence were 153.3, 202.2 and 102.6 per 100,000 
population. Only the Ulytau region had a cancer incidence less than the control region. The Arys and Irgiz district have 1.17 and 1.54 times the incidence rates observed in the Zhanaarka district. As for the Ulytau region, the incidence rate observed for the time period 2003 - 2014 was 1.27 times less than the control region and 1.84 times less than the Republic of Kazakhstan.

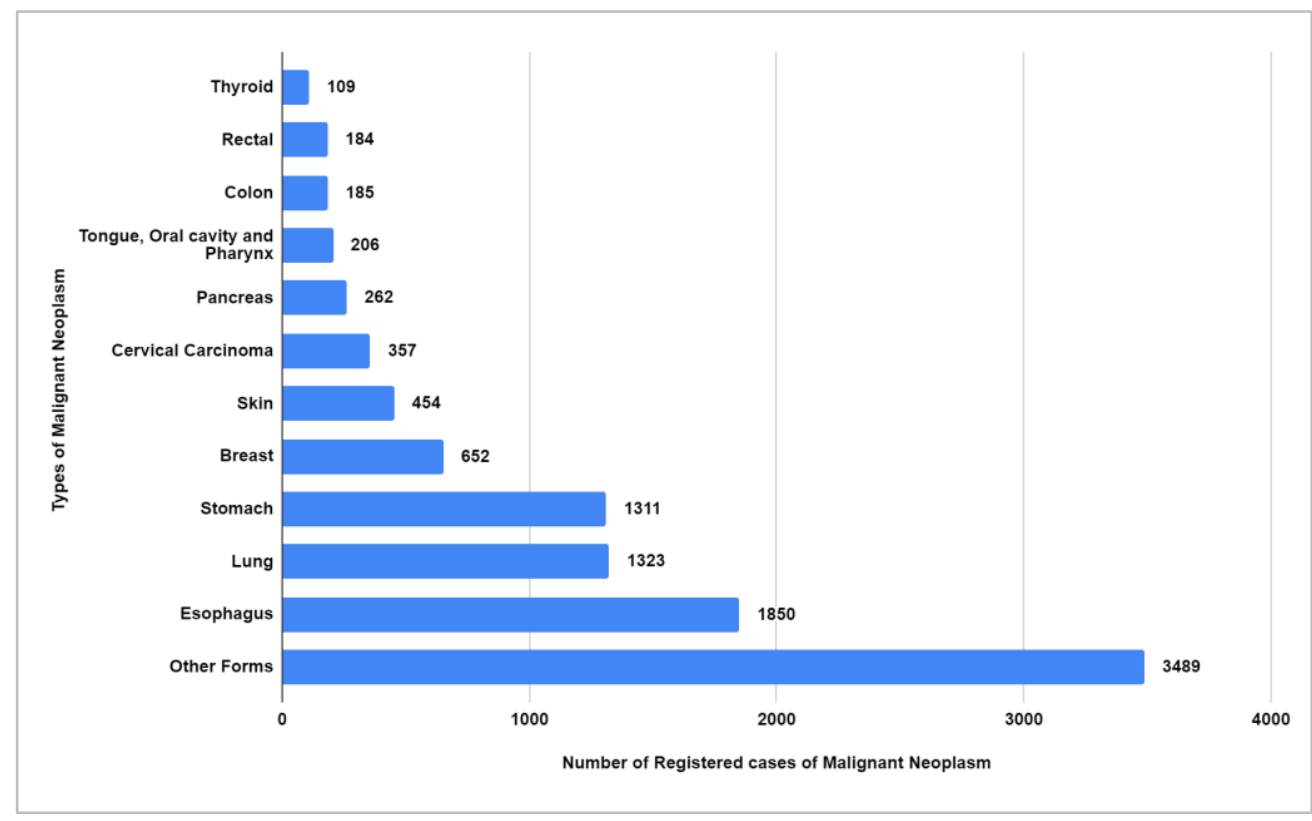

Figure 9: Different recorded cases of Malignant Neoplasm through the 11-year period (1999 - 2009). [Source: data extracted from (Igissinov et al., 2011)]

Another research paper (Igissinov et al., 2011) collected data on multiple types of cancer that affected the population of the Aral Sea region. This data was collected during an 11-year period starting from 1999 and lasting until the end of 2009. Figure 9 shows the distribution of types of cancer observed during this time period. A total of 10,382 cancer incidents were recorded. Among these, oesophagus cancer is the most prominent with $17.8 \%$ occurrence rate, at second and third positions, are Lung cancer and Cancer of the Stomach with close, $12.7 \%$ and $12.6 \%$, occurrence rates.

\subsubsection{Discussion}

The decline of the great Aral Sea began in the late 1960s. There are several factors that contribute to the desiccation of the saline lake such as superfluous withdrawal of water from the tributary rivers, macro and microclimatic changes, inefficient agricultural practices, lack of sustainable industrial practises etc. This decline in the water level brought about several challenges for the population that relied on the lake for sustenance. Hazardous health 
conditions resulted from this environmental change. The dry lake bed which is rich in salt concentration and infused with lethal pollutants were picked up by the dust storms and spread across the Aral Sea region.

\section{Pollutants}

Over the years the agricultural practices in the Aral Sea region relied on extensive use of chemical pesticides such as dichlorodiphenyldichloroethylene (DDE), hexachlorocyclohexane ( $\mathrm{HCH})$, butiphos, propanide, and dichlorodiphenyltrichloroethane (DDT) which were banned in the rest of the world (Sakiev, 2016). Additionally, wastewater contaminated with toxic chemicals from 146 different collector-drainage systems was discharged into the Syr Darya River (Sakiev et al., 2017). This resulted in the radical contamination of the Syr Darya River with heavy metals and persistent organic compounds (POC) that include polychlorinated biphenyl, polychlorinated dibenzodioxins and polychlorinated dibenzofurans. These chemicals were used as coolants and lubricants in both industrial and mining activities, with a primary source of discharge of refineries such as Ispat-Karmen, Balkhashmys, Akchatau, Zhezkazgantsvetmet, Shalkiya and Shymkent (United Nations, 2000). Furthermore, studies on body burdening pollutants showed traces of hexachlorobenzene (HCB), dichlorodiphenyldichloroethylene (DDE), hexachlorocyclohexane $(\mathrm{HCH})$ and dichlorodiphenyltrichloroethane (DDT) chemicals in the blood plasma of pregnant women. Polychlorinated biphenyl (PCB) and Persistent organic compounds (POC) were also found in their breast milk. The blood lipid among the children in the study region contained DDT and $\mathrm{HCH}$ which are typical representatives of organochlorine compounds (Ataniyazova and O.A., 2003; Ataniyazova et al., 2001). The organochlorine compounds are carcinogenic and cause neurological damage and chronic health issues (Jayaraj et al., 2017). Researchers collected samples of butter, cottonseed oil and cooking oil to test whether the contaminated water affected the food chain of people around the Aral Sea region. They found, 2,3,7,8tetrachlorodibenz-para-dioxin (TCDD) in the cottonseed and HCH in butter, sheep meat, eggs, carrots and onions (Herbst, 2006; Wæhler and Dietrichs, 2017). The dust storms were one of the prominent means of widespread for chemical pollutant transport through the area.

\section{Discussion on health}

As discussed previously, the dust-storms were claimed to be the cause of respiratory diseases such as chronic bronchitis, bronchial asthma, and tuberculosis. In a study conducted by Kunii et. al, 2003 and Bennion et. al, 2007 in Uzbekistan, no strong relationship was found between the dust storms and the respiratory issues. However, this does not mean that the sandstorms 
are harmless. Even though no direct connection to respiratory diseases were found the dust storms could still indirectly affect the demographics of the Aral Sea region.

Psychological disorders observed around the Aral Sea region could be an example of indirect effects of the dust storms. There were reported cases of decreases in, short-term memory and long-term memory and attention span; different psycho-emotional disorders and depression. The dust storms deposited harmful chemicals on the fertile soil bringing about the decline in agricultural production. The inhabitants of the region who were dependant on agriculture were now unemployed. Poor economic conditions, unemployment and deteriorating health conditions take a toll. These factors could lead to increased stress and depression. Studies conducted to assess the mental condition included the SCL - 90 Questionnaire. According to the questionnaire, $48 \%$ of the test subjects (56 out of 118) reported stages of somatic symptoms connected with mental distress which was above the standardized cut point of 0.36 . However, these survey-based studies are heavily reliant on the self-assessment of a patient. There is no solid standard to weigh the opinion of a patient. Moreover, these studies are cross-sectional with randomly selected participants thus the selection of patients for the study, the socio-economic conditions of the selected population and several other factors act as an uncontrollable variable thus making the result of the study less reliable.

Several speculations have been made about the deteriorating central nervous system among the population of the Aral Sea region. The majority of the victims of these diseases are in the age range 20 - 50 year. Certain research claims that highly toxic substances such as lead, nickel and chromium cause asthenia and psychogenic disorders (Sakiev, 2016). However, the studies conducted in this discipline are limited thus making it difficult to draw wellgrounded conclusions.

Studies conducted on the mortality of women in the Kyzylorda region show that $16.2 \%$ of deceased women were of reproductive age (15-49 years). According to some studies, the reason for this high woman, infant and perinatal mortality could be due to improper diet or malnutrition. Other studies show an alarmingly high amount of PCB, DDT, TCDD and other toxic chemicals present in children's blood and breast milk in the Aral Sea region when compared to local and international study regions. Studies also show the presence of these chemical pollutants in food products. Though several types of research talk about the exposure and body burdens of pollutants, the precise health effects of these have not been completely understood. 
For the analysis of Disabilities and Malignant neoplasm, Catastrophe zone, Crisis zone and Pre-Crisis zone were chosen. Surprisingly, the prevalence of disabilities is not the highest in the catastrophe zone as hypothesized. Instead, the presence of Cardiovascular, Eyes and Physiological disabilities were highest in the Crisis zone. There was no clear explanation mentioned in the study for this observation. Figure 7 shows the predicted incidence of disabilities for the year 2023 based on the data collected from 2004 - 2013. However, the reliability of the prediction is questionable. Predicting 10 years into the future based on 10 years of past requires many assumptions which often manifest large errors when compared to the future. This has also been acknowledged by the authors (Sakiev, 2016). The average incidence rates of malignant neoplasm of the three zones of interest were compared with that of Zhaanarka the control region and the whole Republic of Kazakhstan. The catastrophe and crisis zone had incidences higher when compared to the rest. Diving deeper, within the zones, the Aral region had the highest recorded incidences of Malignant neoplasm with esophagus, Lung and Stomach related cancer as the highest prevailing forms. The research found that the inhalation and oral intake of nickel, cadmium, arsenic, selenium, mercury, manganese, phosphate, nitrate, copper, cobalt and chromium correlated with the incidence of cancer among the population of the Aral Sea region.

Numerous studies hypothesize the adverse effects of drying the Aral Sea on human health. A majority of the claims are centred around dust storms causing respiratory, psychological and other disabilities observed in the Aral Sea region. The study conducted during 2000 on the lung conditions of the children living in the concerned areas revealed no evidence of respiratory disease symptoms among them (Bennion et al., 2007; Kunii et al., 2003). Other health issues were related to the nutrition and food habits of the population. Prevailing poverty resulted in woman and infant morbidity due to malnutrition. The residents around the Aral region faced challenges like unemployment, low incomes and closure of enterprise due to the Aral disaster (Sakiev, 2016). This might have led to an increase in local agricultural practices for sustenance. Negligent agricultural practices that heavily relied on chemical fertilizers and pesticides contaminated the soil and water. Unrestrained runaway of industrial pollutants into the lake aggravated the environmental situation. Chemical pollutants and Persistent Organic Pollutants entered the human body through the food chain. Biowarfare testing in the area along with Radioactive mineral mining could have also contributed to deteriorating health conditions (Bersimbaev and Bulgakova, 2015; Gorvett, 2017; Granit et al., 2010). Studies show the connection between these pollutants and health issues. High rates of Malignant neoplasm and the discussed disabilities were probably caused by 
these pollutants. The studies conducted in this domain are mainly crosssectional and some are case-controlled. These studies have several uncontrollable variables which makes the results less reliable. There was also a problem of information mismatch (Crighton et al., 2003) between official data and the observed data. However, there is not enough evidence to confirm this claim. The majority of the research was conducted during the 1990s and the early 2000s. A decrease in the research in recent years has been observed. Despite multiple evaluations, there seem to be no well-grounded results to either accept or reject the hypothesis of adverse health effects due to the drying of the Aral Sea. 


\section{Chapter 4: Restoration of Great Salt Lakes}

This section of the report concentrates on the analysis of three different approaches taken by Kazakhstan, Uzbekistan and Iranian governments towards the common issue of a drying Salt Lake.

The Northern Aral Sea was restored by controlling the water withdrawal from tributary rivers under the Kazakhstan government, the Southern Aral Sea was left without serious plans of restoration and the dry lake beds were used for oil and mineral extraction under the Uzbekistan government and the Lake Urmia is in the process of restoration by water transfer activities from neighbouring water sources under the Iranian government. Analyzing the issue from three different perspectives could help to understand the level of necessity for restoring a drying lake.

\subsection{Lake Urmia and its Restoration Efforts}

Lake Urmia started shrinking at a rapid rate since 1995 as shown in Figure 10a. The water level dropped below the minimum level required for ecological balance $(1274.1 \mathrm{~m})$ by 2002. In the efforts of restoring Lake Urmia, the Iranian government announced the Urmia Lake Restoration Program (ULRP) under the Urmia Lake Restoration Program National Committee (ULRNC) headed by the Vice President to save the lake and protect the ecological balance of the area (ULRP, 2015b). The 25-year vision of the lake is defined as "a lake with enough water for sustainability, beautiful views and rich biodiversity, which people and local societies use its capacity wisely and maintain its sustainability. The lake is a suitable platform for improving cooperation between organizations in related provinces." As a result, ULRP was designed to confront distinct difficulties in six packages.

The six packages include:

1. Control and reduction of water consumption in the agricultural sector

2. Control and reduction in the withdrawal of surface and groundwater in the Urmia Lake Basin (ULB)

3. Initiatives on Protection and mitigation of negative impacts

4. Studies and software measures

5. Facilitate and increase the water volume entering the Lake throughout structural measures

6. Water supply from new water resources 
Implementing these packages involve different actions in agriculture, infrastructure, policy and legal framework as well as adjustments to the socioeconomy realm. Approved strategies related to agriculture include (i) Prevent unauthorized withdrawals from surface and groundwater resources. (ii) Inventory Lake Urmia Basin wells and installing smart meters to control withdrawal in order to increase rivers' inflow to Lake Urmia. (iii) Control and reduce water use in the agricultural sector. In total, 88 projects were defined with a majority of them concerning water use by agriculture. This sector alone consumes $90 \%$ of water resources in the basin. Among these projects, reducing water consumed by agriculture through increasing water use efficiency, preventing the illegal use of water, people participation in different projects especially on changing crop pattern and applying new technology for irrigation such as drip irrigation. There are 90,000 wells in the Urmia basin of which $50 \%$ are illegal (ULRP, 2015a). Preventing illegal wells and installing digital smart water meters for each well are the main actions in this regard.

ULRP has several water transfer activities included in their program. Water will be transferred from (1) wastewater treatment plants, (2) the Zab River and (3) transfers through Hasanloo Dam. In addition to these, Inter-basin transfer projects have been proposed from the Aras River and the Caspian Sea. To achieve the restoration of Lake Urmia, wastewater collection networks will be installed, dams will be constructed, river networks will be renovated and reconstructed and canals will be added to the conveyance network (ULRP, 2018). Among the six packages, the first four packages have already been implemented and the current ongoing activity is in water transfer. This report will focus on the analysis of water transfer activities taken up to restore the level of Lake Urmia.

\subsubsection{Water Transfer Activities}

Minimum water level required for Lake Urmia's ecological balance (1274.1 $\mathrm{m})$. This is essentially an ecological threshold for the lake, beyond which "there is an abrupt change in the ecosystem quality, property or phenomenon, or where small changes in an environmental driver produce large responses in the ecosystem" (Groffman et al., 2006). Lake Urmia's water level dropped below the minimum level required for ecological balance $(1274.1 \mathrm{~m})$ by 2002 . During 2015 it was $4.04 \mathrm{~m}$ below the required level for ecological balance and $8 \mathrm{~m}$ below its recorded highest level of $1277.95 \mathrm{~m}$ (ULRP, 2015a) as shown in Figure 10b. An annual inflow of 3.1 BMC (Billion Cubic Meter) of water is necessary to maintain the ecological level of Lake Urmia (Aquapedia, 2015). As of 2016, the recorded inflow was at 1900 MCM (Million Cubic Meter) (ULRP, 2019a). Thus, a significant portion of the restoration program deals with the transfer of water from various sources into the lake. 
According to the ULRP program, the operating time is 10 years which is split into three phases (ULRP, 2017) as shown in Figure 10c:

1. Stabilization Phase (2014-2016): Implementing projects to reduce lowering of water level

2. Restoration Phase (2016-2023): Implementing solutions to raise the water level

3. Final Restoration Phase (2024): Ensuring the sustainability of the lake
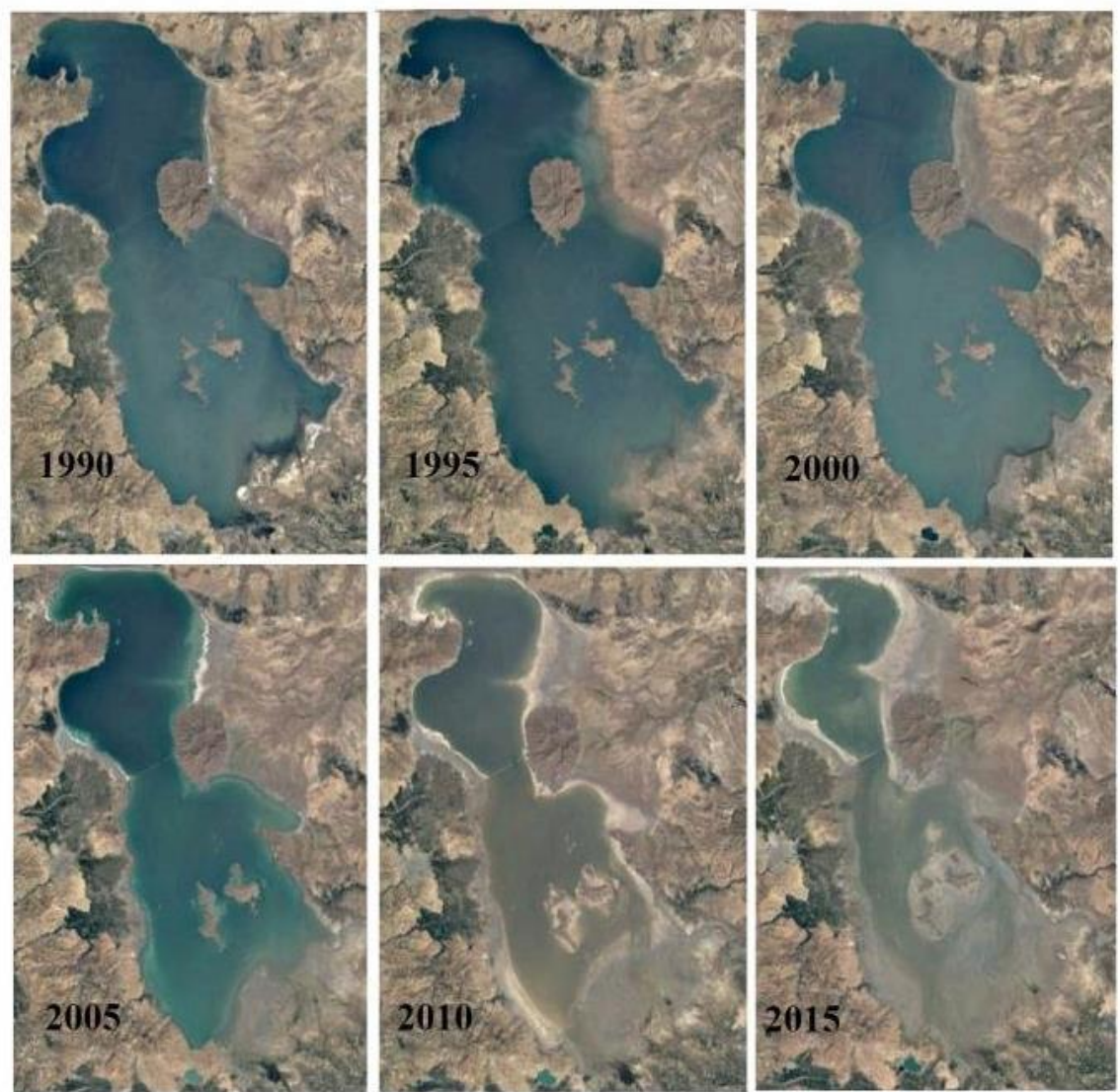

Figure 10a: Trend of reduction in the shoreline of Lake Urmia [Source:(Ghashghaie and Nozari, 2018) 


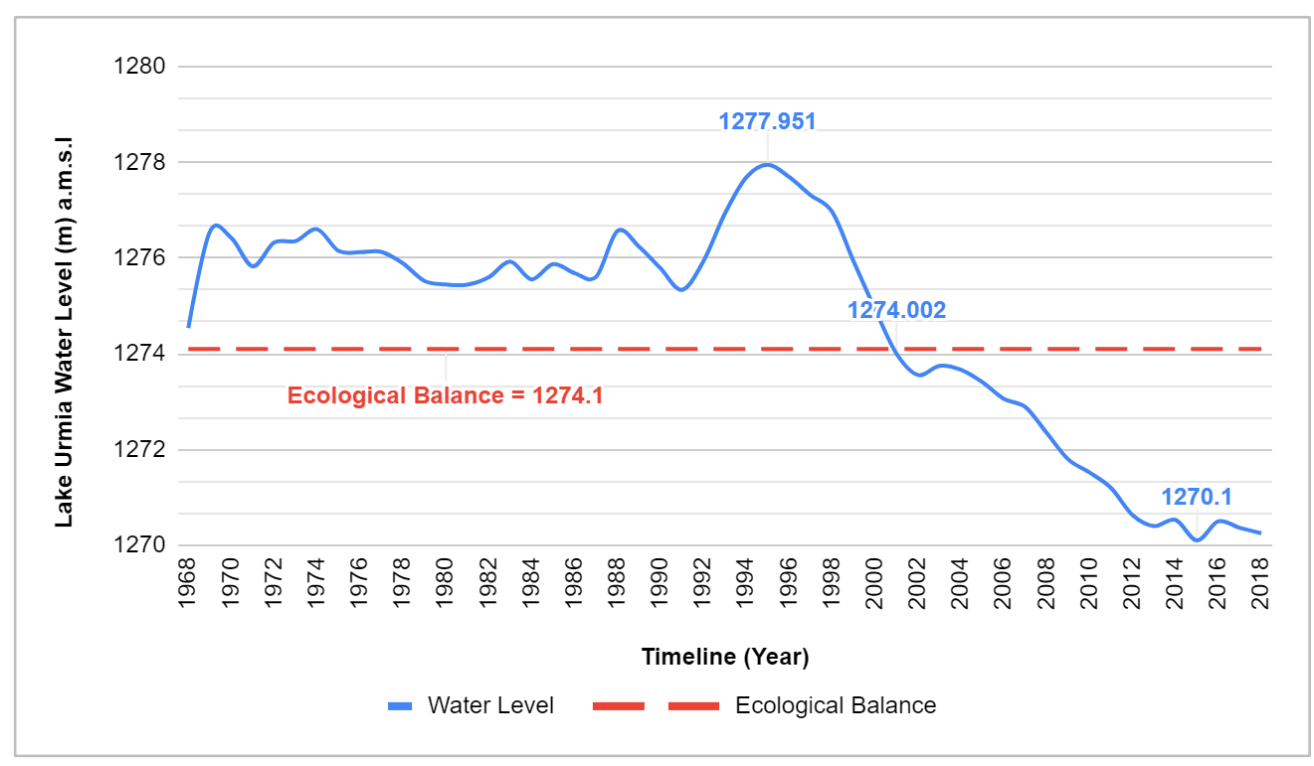

Figure 10b: Water Level of Lake Urmia for the period 1966 - 2018

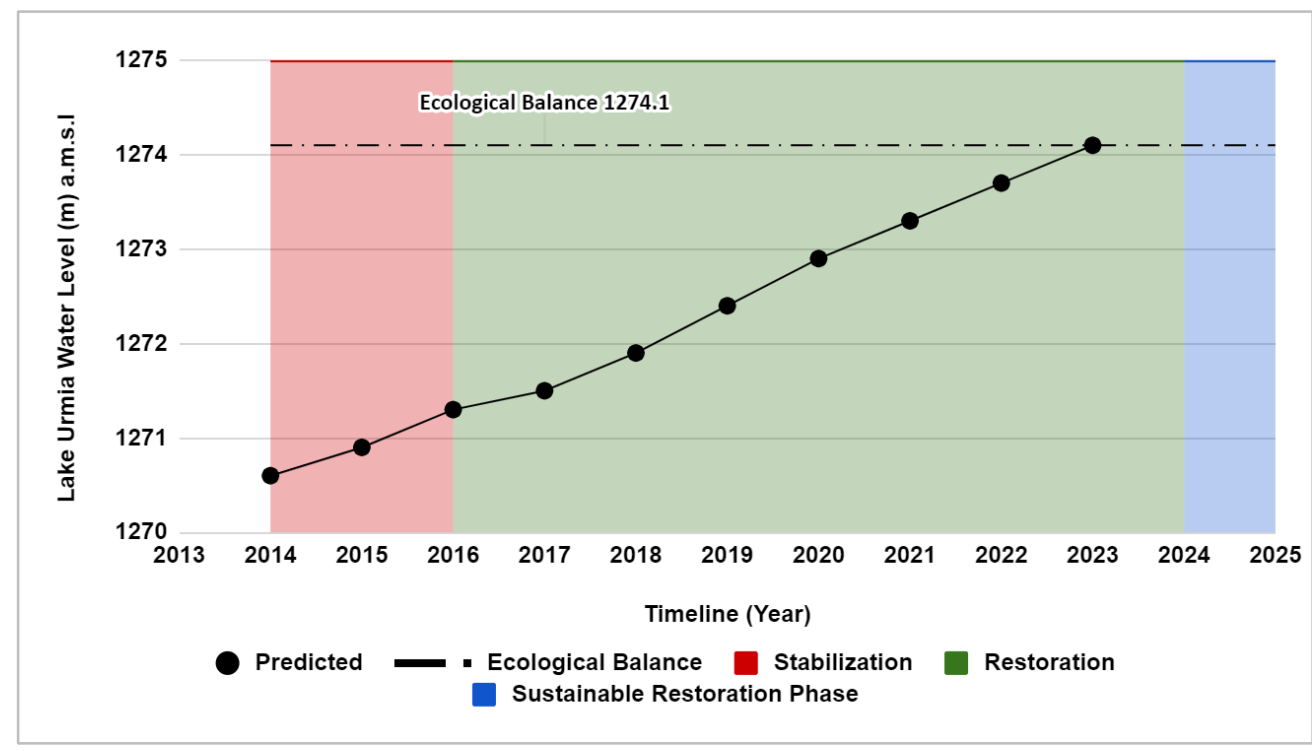

Figure 10c: Projected water level for Lake Urmia

From the six packages adopted by the ULRP, as mentioned, packages 5 and 6 deals with water transfer activities. The implementation of the projects associated with these packages will require the construction of dams, tunnels and refurbishment of current infrastructure. The water transfer projects will not only be from water bodies, but a part of the transfer will be from wastewater treatment plants. 


\subsubsection{Water Transfer From The Aras River To Lake Urmia}

The project was launched in 2010 by the Iranian government to transfer 600 MCM (Million Cubic Meters) of water annually from the Aras river to Lake Urmia (Zaman, 2013). By February 2014, preparatory work had already begun, anticipating that the launch of the project would begin at the end of the Iranian year (Rajabova, 2014) but by 2016 the project was cancelled as it was not costeffective (approximated cost was \$1.2 Billion) (Zaman, 2013).

The Iranian ecologists did not promote the project as they expected that it would adversely affect the Aras river's ecosystem as this project threatened the drinking water supply and irrigation supply of people that relied on the Aras river.

The Aras river has a drainage area of $102,000 \mathrm{~km}^{2}$ mostly in the former Soviet Union and Iran. There are less than $10,000 \mathrm{~km}^{2}$ in Turkey (UNDP, 2010). One of the challenges presented with this project was settling transboundary agreements. Countries adjacent to the river are Turkey, Armenia, Azerbaijan and Iran. Iran managed to initiate agreements with Armenia and Azerbaijan. The agreement with Azerbaijan would allow Iran to use water and energy resources at the same level as Azerbaijan (Rajabova, 2014).

\subsubsection{Water Transfer From The Caspian Sea To Lake Urmia}

Offered for discussion is the water transfer project from the largest enclosed sea in the world, the Caspian Sea, to Lake Urmia. Considering its coastal zone and biodiversity, the Caspian Sea region is one of the most valuable ecosystems in the world (Mamaev and I, 2002). The Caspian Sea is surrounded by five countries, namely, Azerbaijan, Kazakhstan, Iran, Russia and Turkmenistan. It should come as no surprise that Iran is not the only country considering refuge in the Caspian Sea. Other transfer projects proposed are transferring water from the Caspian Sea to the Aral Sea and to Garabogazkol lake (Diba, 2016). Considering this, transferring water to Lake Urmia will likely cause international tension.

Apart from the political issues, the other factor to be considered is the height difference between the Caspian Sea and Lake Urmia. Lake Urmia is $1316 \mathrm{~m}$ above the Caspian Sea which makes it economically inefficient to transfer this water (Khatami and Berndtsson, 2013) but this is not the only reason for the project not proceeding. The risk of damaging the ecosystem of the Caspian Sea was too high, which is why this idea was not fully supported. 


\subsubsection{WasteWater transfer from Treatment Plants To Lake Urmia}

According to the ULRP time schedule, by the end of the program's restoration phase, water transfer from wastewater treatment plants will supply Lake Urmia with $300 \mathrm{MCM}$ of treated water annually at max capacity. The first phase of the water supply of $100 \mathrm{MCM}$ from wastewater treatment plants was scheduled for 2018 .

In 2010, Iran had 129 wastewater treatment plants which covered 13 million people (Massoud, 2010) among which 19 treatment plants are involved in ULRP under the East Azerbaijan, West Azerbaijan and Kurdistan Regional Water Authority as shown in Table 1.

Table 1: Wastewater treatment plants within the ULRP (ULRP, 2018)

\begin{tabular}{|c|c|c|}
\hline $\begin{array}{c}\text { Regional Water } \\
\text { Authority }\end{array}$ & $\begin{array}{c}\text { Number of } \\
\text { Wastewater Treatment } \\
\text { Plants }\end{array}$ & $\begin{array}{c}\text { Effluent Volume } \\
\text { (MCM) }\end{array}$ \\
\hline West Azerbaijan & 10 & 121 \\
\hline East Azerbaijan & 8 & 161 \\
\hline Kurdistan & 1 & 19 \\
\hline Total & 19 & 300 \\
\hline
\end{tabular}

The overall project cost for ULRP is US $\$ 1.3$ billion of which US $\$ 114.35$ million is predicted to be used for wastewater transfer activity (ULRP, 2019b). Activities involved in transferring treated wastewater to Lake Urmia are: constructing wastewater treatment plant, installing wastewater collection network and devices in various cities, pump stations and treated water transfer pipelines. Given that design deficiencies account for $68 \%$ of effluent violation (Mansoor, 2011), it is imperative that the design deficiencies which include planning, as well as construction deficiencies, are mitigated prior to the implementation of these activities.

\subsubsection{Cost Analysis of ULRP}

The restoration process for drying great lakes is financially demanding. The overall ULRP restoration is estimated to cost US $\$ 1.3$ Billion. To better understand the distribution of cost, Lake Urmia restoration project outline and the respective budget breakdown for the financial year 2015 - 2016 (ULRP, 2015a) has been expressed below. The budget for the year 2015 - 2016 was US 
$\$ 626,592,000$ as shown in Appendix A (almost half of the estimate in one year of 10 year project)(ULRP, 2019b).

\subsection{Restoration of the Northern Aral Sea}

During the period 1960-1986, the water level of NAS dropped from $53.40 \mathrm{~m}$ to $41.02 \mathrm{~m}$ resulting in a reduction of the shoreline (CAWater, 2019) as shown in Figure 11a and 11b.
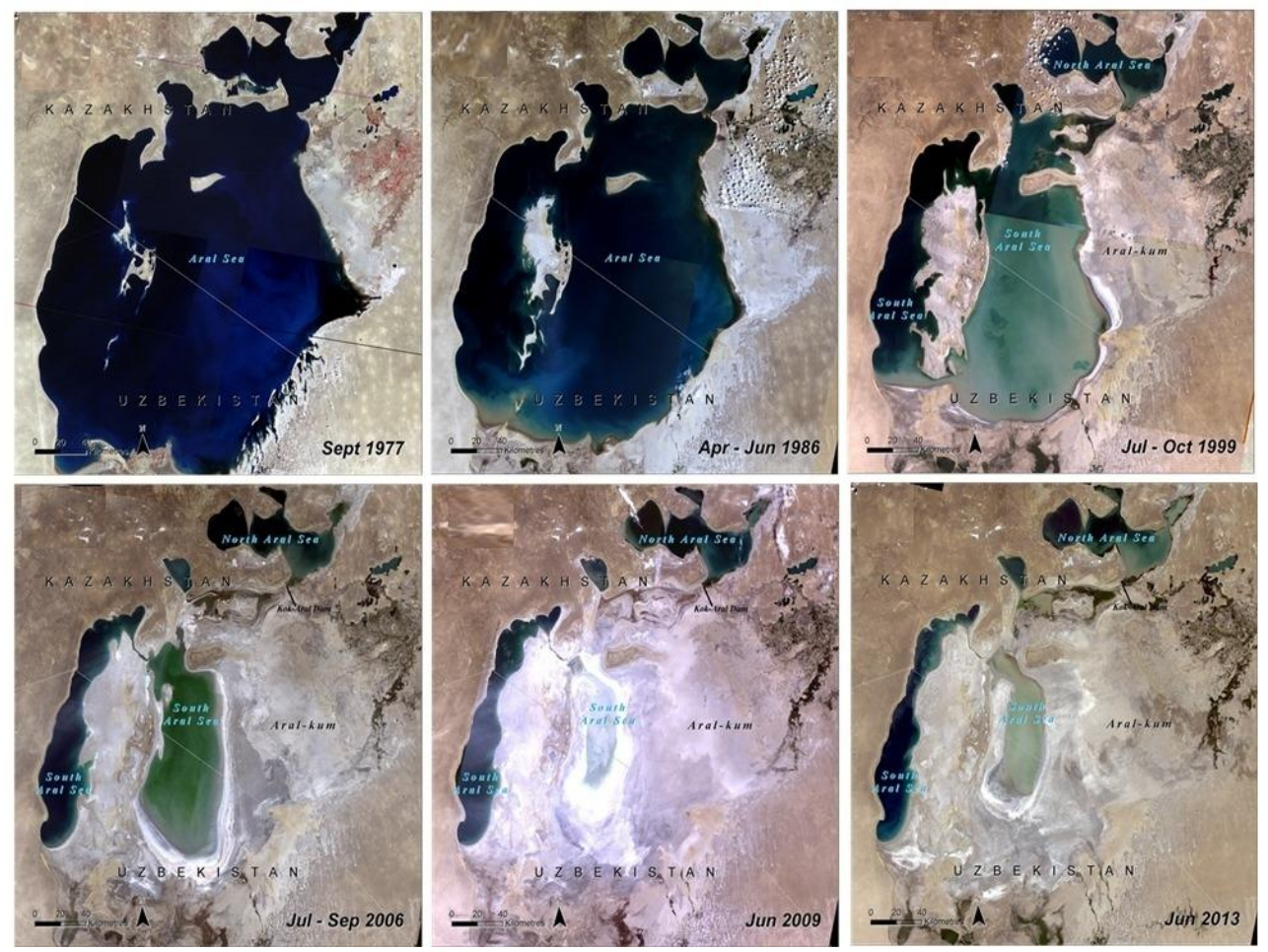

Figure 11a: Trend of reduction in the shoreline of the Aral Sea for the year 19772013. [Source: Modified from (WMO, 2014)] 


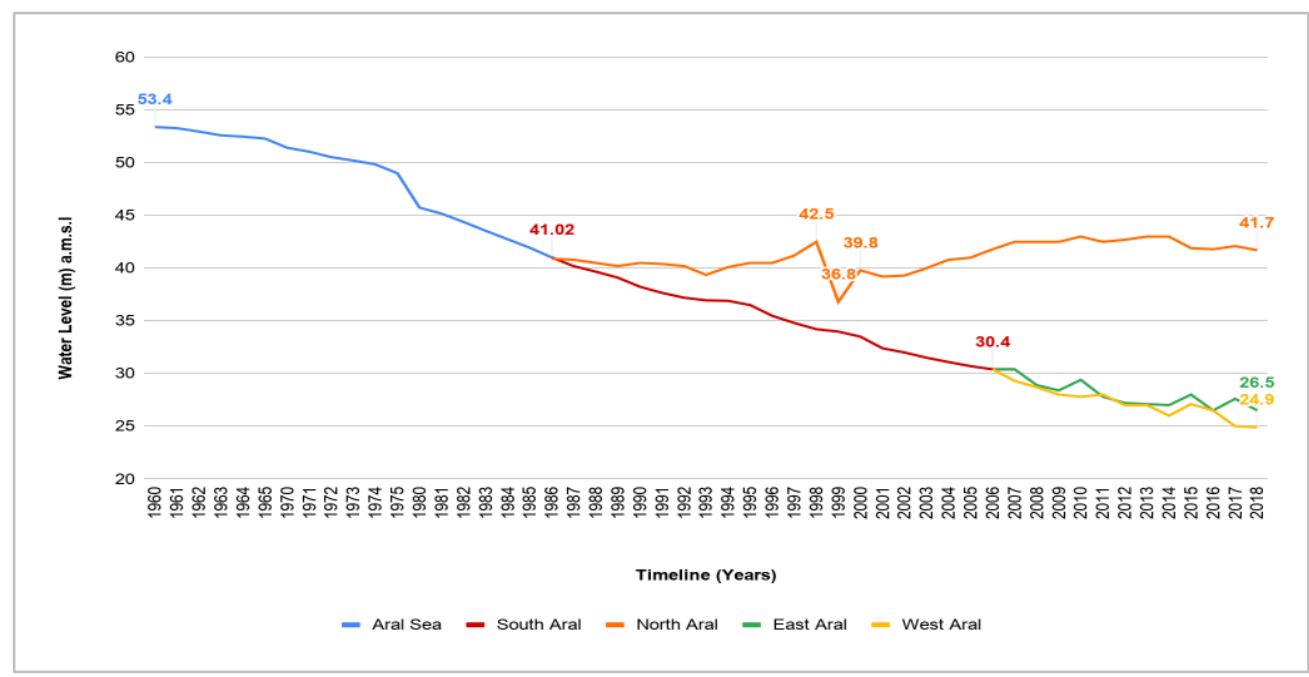

Figure 11b: Fluctuation in water level in Aral Sea during 1960-2018. [Source: data extracted from (CAWater, 2019)]

To restore the Aral Sea, heads of the five countries in Aral Basin introduced the Aral Sea Basin Programme (ASBP) in 1994. ASBP was funded by the International Fund for Saving the Aral Sea (IFAS) to improve the ecology and socio-economic situation in the Aral basin (World Bank, 1998). The main funding partners were United Nations Development Programme(UNDP), United Nations Environmental Programme (UNEP), World Bank, Asian Development Bank (ADB), Global Environmental Faculty (GEF), European Bank for Reconstruction and Development (EBRD), Technical Aid to the Commonwealth of Independent States (TACIS), Kreditanstalt Fur Wierderaufbau (KFW), German Development Bank, ERA Kuwait and United State Agency for International Development (USAID) (World Bank, 1998).

The program consisted of 17 Activities, each with 4 components. This thesis focuses only on "Rehabilitation of the Northern Aral Sea" which was under the project "Syr Darya Control and Northern Aral Sea Phase 1 (SYNAS)". According to researchers Micklin and Aladin, the total cost for reviving the full Sea would require US \$16 billion. The countries in Aral Basin Kyrgyzstan, Turkmenistan, Tajikistan, Kazakhstan and Uzbekistan) except Kazakhstan focused to expand irrigation and Kazakhstan tried to restore the part of the lake which was within its territory (Micklin and Aladin, 2008). 


\subsubsection{Syr-Darya Control and Northern Aral Sea Project (SYNAS)}

This project had defined objectives.

1. To secure the North Aral Sea which will improve the ecology, environment and biodiversity in the delta which in turn would improve the health of humans and animals living nearby.

2. Increase agricultural and fishing yields in the region.

In 1992 the local authorities built an earthen dyke to stop the flow of water from NAS to SAS. However, by 1999 substandard construction materials could not withstand the increase in water level and windstorms. A detailed study was carried out on the construction of a new dyke. The new dyke was recommended to have a concrete structure and better hydraulic structures as than the existing ones which were choked in winter due to ice formation. Finally, with the help of the World Bank, the Kazakhstan government initiated the SYNAS-1 project. The project lasted from 2001-2008 with an overall cost of US $\$ 83.34$ million. The project had six activities as mentioned below and their respective monetary distribution are shown in Appendix B.

The six activities Under the project SYNAS are:

1. Recuperation of Northern Aral Sea

2. Improvement of Hydraulic regulators for the Syr Darya

3. Rehabilitation of the Chardara Dam

4. Restoration of Aquatic resources and development of Fisheries

5. Monitoring and Evaluation

6. Project Management

\subsection{Restoration of The Southern Aral Sea}

The water surface in the South Aral (including West and East) was $36,960 \mathrm{~km}^{2}$ in 1989 and 6,717 $\mathrm{km}^{2}$ in 2011 (Micklin, 2014) which indicates, 30,243 km of dry lake deposit that must be restored. Restoring the SAS which is greater than the NAS surface area, would require more than US \$83million. Hence, the government of Uzbekistan has invested in the exploration of oil and gas (\$110.2 million US dollars), salt extraction, plantation of trees on the dry lakebed and tourism in the SAS. These programs promise economic growth and employment opportunities to the people living in the region.

\subsection{Discussion}

\section{Discussion for Lake Urmia}

The government of Iran has recognized the deteriorating condition of Lake Urmia since 2013 and has made profound attempts at restoration. In the attempt 
of reducing dust storms, they considered water transfer activities to raise the lake's water level. This included using treated wastewater to restore the lake. However, wastewater transfer relies on the efficiency of Iran's wastewater recycling. The advantage of wastewater transfer is that there is no ecosystem disruption for the donor waterbodies and Lake Urmia will receive the muchneeded consistent input supply of water. However, the drawback is that treated wastewater can result in eutrophication from the nutrient load. A low standard of wastewater treatment can also result in untreated nutrients to form sediments and effectively reduce the water holding capacity of the lake in the future as represented in Figure 12.

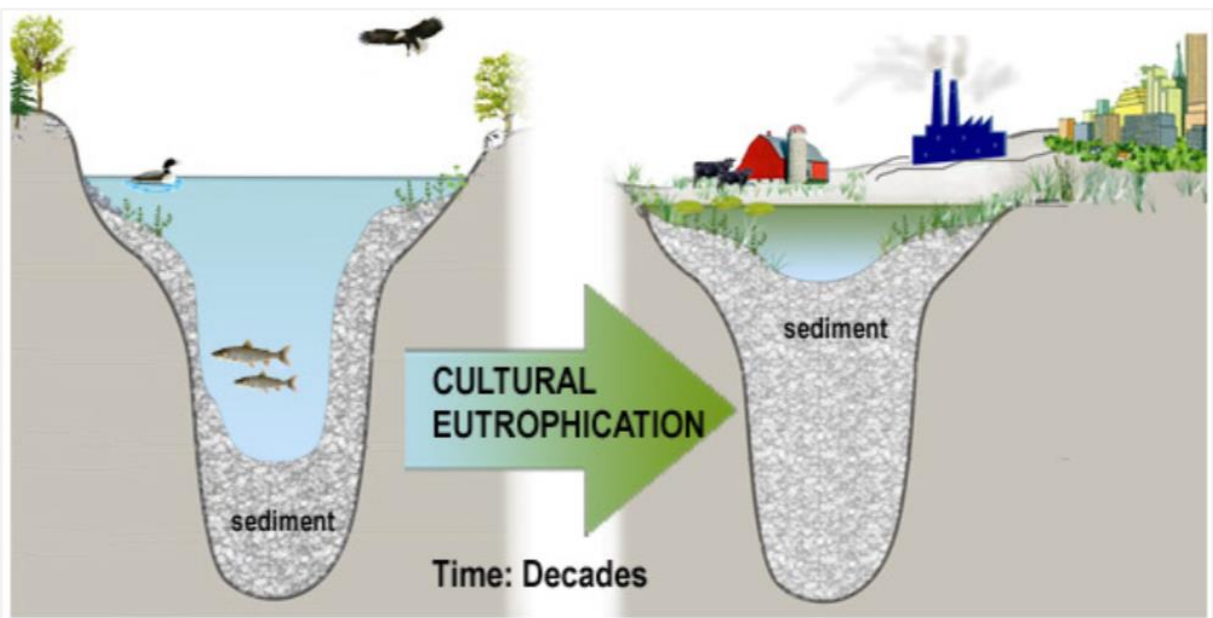

Figure 12: Effects of Eutrophication: Reduction in the total holding capacity of the lake. [Source: (RMBEL, 2019)]

The 19 wastewater treatment plants in 3 provinces under ULRP, as shown in Table 1, has a combined output of $300 \mathrm{MCM}$ of treated wastewater annually. Treating wastewater is expensive. According to the global trends, the wastewater treated in developing countries constitutes only $28-38 \%$ whereas the remaining is let into the water bodies without treatment (UNESCO, 2017). Due to cost, municipal wastewater (which is mostly domestic) is not treated further than secondary biological treatment (Mansoor, 2011). (The standard western wastewater recycling consists of three treatment stages (Pescod, 1992)). Transferring treated wastewater to Lake Urmia is a project with little objections in theory. Concerns lie with the quality of the water entering the lake. Iran has a history of poor wastewater management (Massoud and Ahmad, 2005), where most of the time treatment plants are overloaded (Anon, 2005) and accounts for $68 \%$ of effluent violation (Mansoor, 2011). This water in a lake would cause eutrophication. 
Although a few previous studies indicate inter-basin water transfer as a potential solution, it is not a feasible solution to the environment. Because of a large difference in height $(1,316 \mathrm{~m})$, water movement from the Caspian Sea is not economically feasible (Khatami and Berndtsson, 2013). However, a general thought would imply, one should not add new problems while trying to solve an existing problem, meaning that water transfer activities from the Internationally shared Caspian Sea is likely to cause transboundary conflicts. It is also speculated that the lifespan of Lake Urmia would be reduced by 50 years due to changes in chemical properties if the Caspian Sea is used to restore the water level (Financial Tribune, 2018).

With future prospects in mind, restoring a drying saltwater lake will be worth the cost if efficient means of sustaining the lake are well thought through beforehand. Spreading freshwater over a large surface area comes with added economic advantages and disadvantages. Investing heavily on restoring the lake has a certain potential for economic growth in the future. A restored, selfsustaining lake will develop the biodiversity in the region. This opens up a great opportunity for ecotourism. Ecotourism adds significant value to the economy. For example, in 2006 approximately US \$800 million (Marden et al., 2014) was spent on wildlife viewing and hunting in Utah. Industry output for the tourism sector in the 5 counties surrounding the Great Salt Lake (GSL) in Utah was US \$1.56 Billion. Bird watching in Utah, most of which takes place in the GSL ecosystem, was valued between US $\$ 99,684,000$ to $\$ 189,463,500$ per year. Duck club members and hunters contributed another US \$61.8 million in revenue (Marden et al., 2014). These revenues from ecotourism demonstrate the potential value of restoring Lake Urmia (Marden et al., 2014).

On the other hand, spreading out the water over a large surface area accelerates the evaporation thus demanding more inflow of clean water into the lake, which could be a heavy economic burden if enough profit is not made through the lake. The idea of limiting the water withdrawal from the tributary rivers of Lake Urmia for agricultural activities might not be efficient. Agriculture is important to the economy and provides employment opportunities around Lake Urmia. Employment in agriculture as a percentage of total employment in Iran stands at $19.2 \%$ and the value-added contribution to GDP of Iran stood at $10.8 \%$ in 2015 (UNEP, 2017). Moreover, the restoration programme hasn't been very successful. Figure 13a through Figure 13d shows the predicted vs actual statistics of ULRP. It can be observed that the restoration programme is not keeping up with the expectations. The ULRP expected to reach the ecological balance level by 2023, but with the current trend, this seems like an impossible task. A considerable amount of time and money have been invested 
up till now and the project does not seem to yield any promising results. With the scenario taking a turn for the worse, it would be better to use the restoration funds towards diversifying the economy.

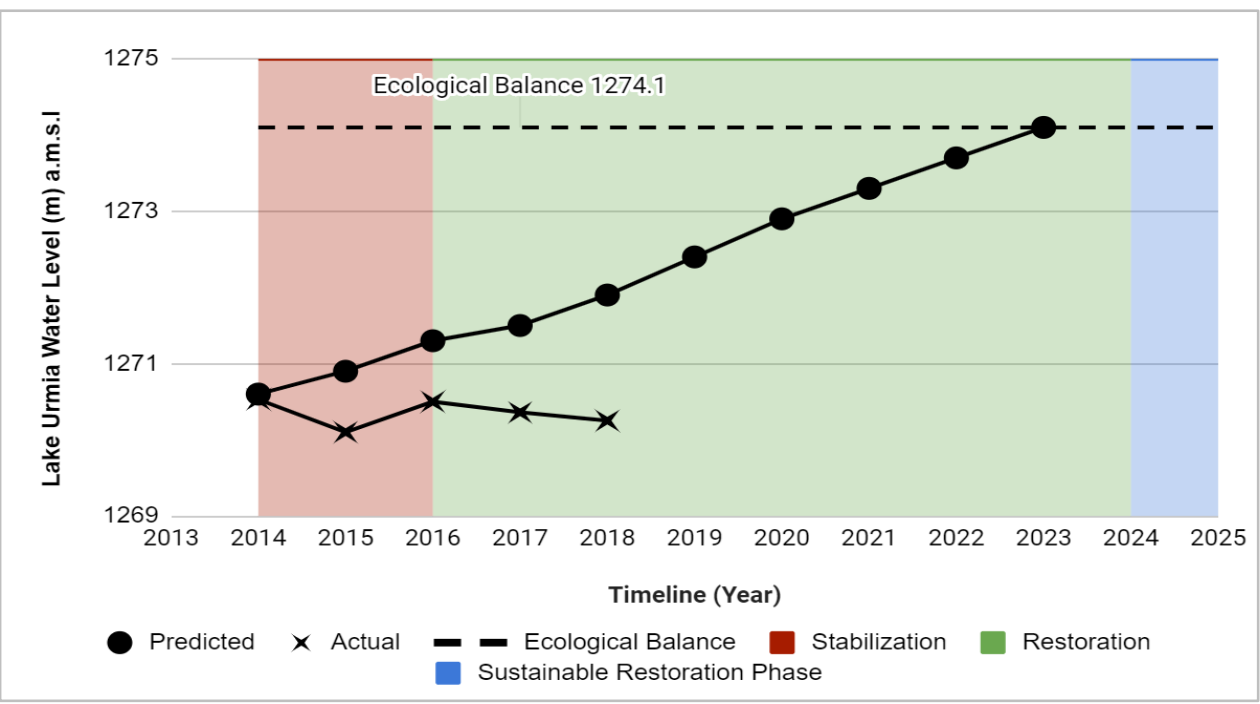

Figure 13a: ULRP Predicted vs Actual water level

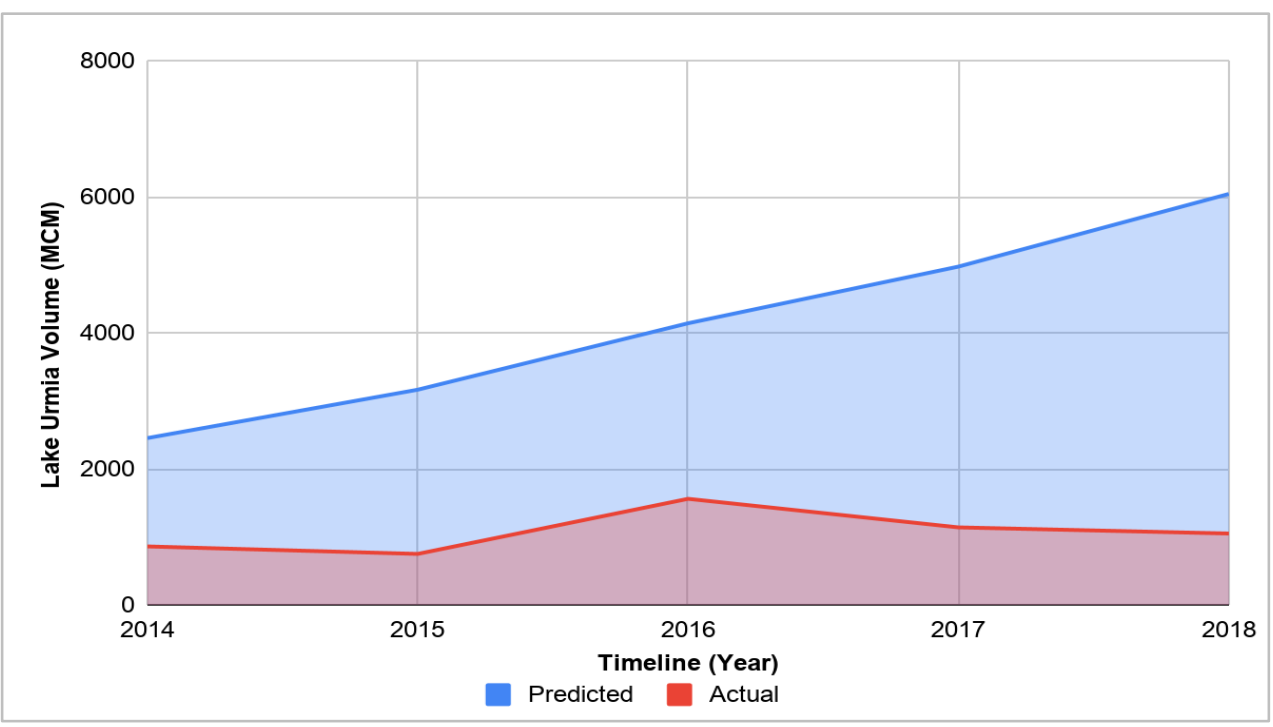

Figure 13: ULRP Predicted vs Actual water volume 


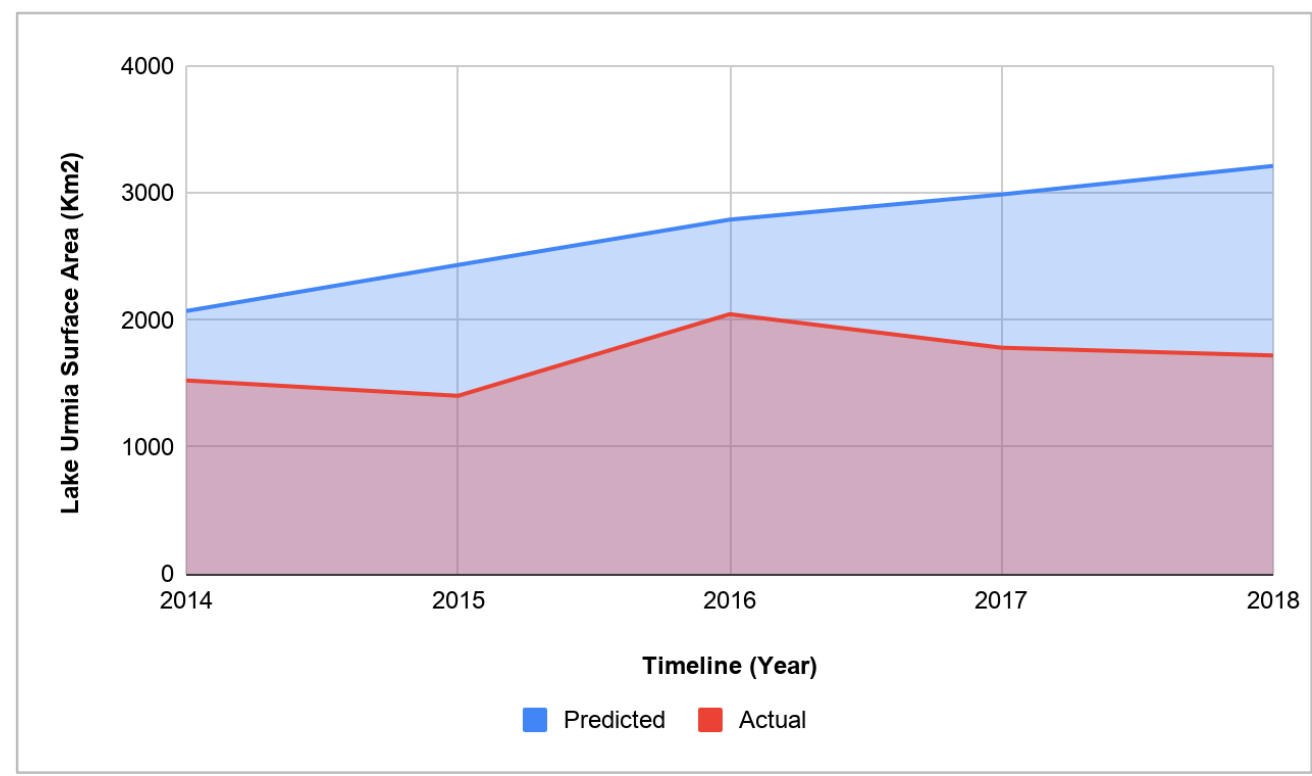

Figure 13: ULRP Predicted vs Actual surface area

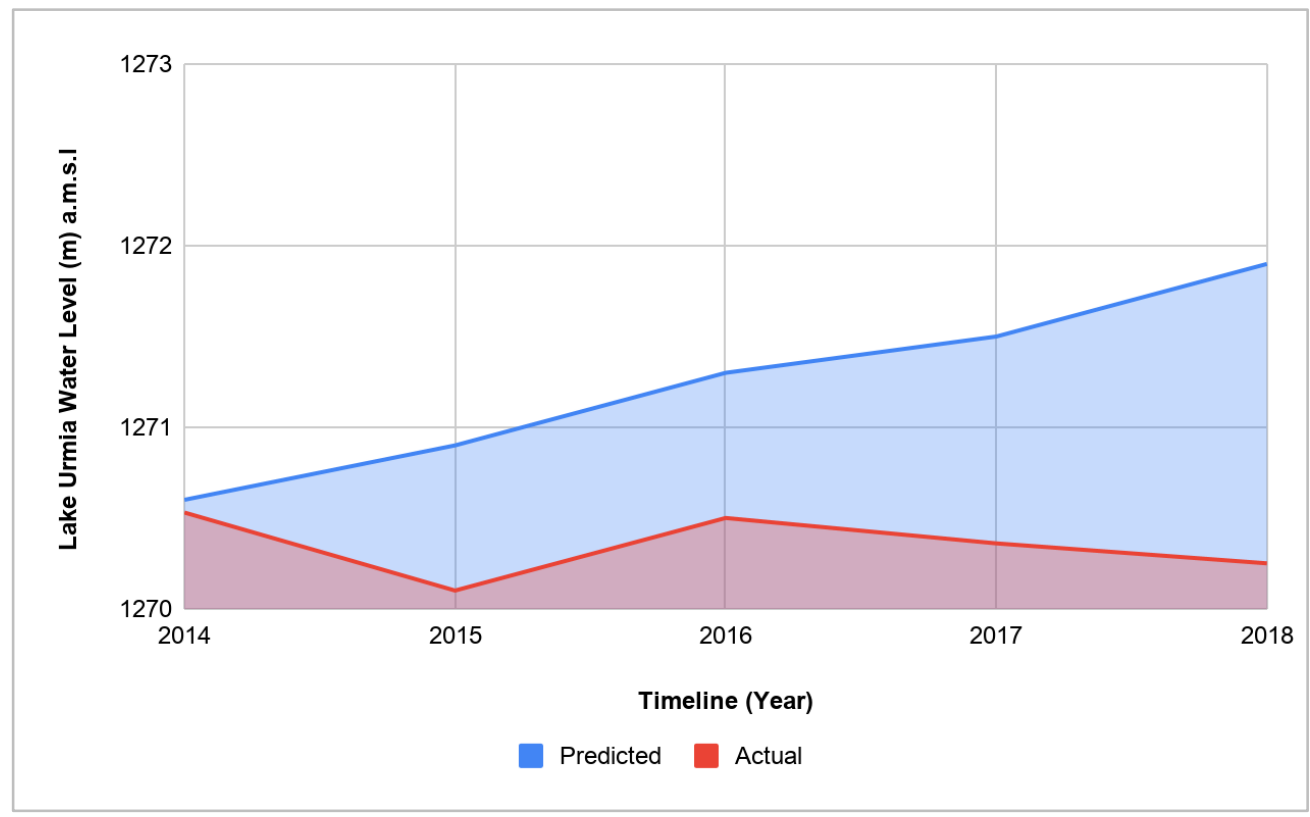

Figure 13: ULRP Predicted vs Actual water level 


\section{Discussion for North Aral Sea}

The acute rise in salinity of the Aral Sea brought about the decline in the fishery. Fishing, the main economy of the region was devastated. The population had to find other means of income for survival. The declining health conditions as a result of polluted dust storms added to the misery. The residents of the Aral Sea region were forced to relocate and diversifying the regional economy for those left was arduous (Living Asia, 2016). To overcome the challenges, the government of Kazakhstan and Uzbekistan took measures. the government of Kazakhstan was responsible for the North Aral Sea (NAS) and the government of Uzbekistan responsible for the South Aral Sea (SAS) took different approaches towards tackling the drying lake problems.

The government of Kazakhstan opted to revive the dried NAS with the help of World Bank, implementation of "Syr Darya Control And North Aral Sea (SYNAS-1)" project required an overall investment of US \$83.34 million of which US \$23.19 million was spent towards building the Kok-aral dam and US \$40.95 million on improving hydraulic control to increase carrying capacity of Syr Darya river. This plan ultimately brought the NAS back to life. There was a decrease in salinity and an increase in water levels which resulted in a now flourishing fish population. The inhabitants, who had occupied themselves with service-based industries like transportation, hotels etc came back to fishing (Living Asia, 2016). With water occupying the drylands, mitigating the dust storm issues, the population could now migrate back to the ASB for food and shelter. A statistical report produced in 2010 shows an economic benefit of US \$13.5 million per year (World Bank, 2011) resulting from the restored NAS. Table 2 outlines the observations made from the implementation of SYNAS-1 Project.

Table 2: Achievements of the SYNAS-1

\begin{tabular}{|l|l|}
\hline \multicolumn{1}{|c|}{ Category } & \multicolumn{1}{|c|}{ Benefits } \\
\hline Fishing & Increase in yield from 52 tons (2004) to 2650 tons (2009) \\
\hline Agriculture & $\begin{array}{l}\text { Increase in yield of rice from 58,500 ha (2001) to 73,300 } \\
\text { ha (2009). Sustainable cropping was practised in 150000 } \\
\text { ha land }\end{array}$ \\
\hline
\end{tabular}




\begin{tabular}{|c|c|}
\hline Health & $\begin{array}{l}\text { There are reports of improved health conditions, but no } \\
\text { sufficient data to validate this claim. }\end{array}$ \\
\hline Salinity level & $\begin{array}{l}\text { The water level increased from } 38 \mathrm{~m} \text { to } 42 \mathrm{~m} \text { with salinity } \\
\text { drop from } 20 \text { gram/litre (2001) to } 11 \text { gram/litre (2018) }\end{array}$ \\
\hline $\begin{array}{l}\text { Ecology } \\
\text { Biodiversity } \\
\text { Management } \\
\text { Structure }\end{array}$ & $\begin{array}{l}\text { 1. Inflow was } 4.318 \mathrm{~m}^{3} \text { in } 2005,3.090 \mathrm{~m}^{3} \text { in } 2015 \text { and } \\
2.814 \mathrm{~m}^{3} \text { in } 2018 \text { with water level } 40.4 \mathrm{~m}, 41.9 \mathrm{~m} \\
\text { and } 42.05 \mathrm{~m} \text {. } \\
\text { 2. The surface area of the North Aral Sea increased } \\
\text { from } 2,940 \mathrm{~km}^{2} \text { to } 3,306 \mathrm{~km}^{2} \text {. } \\
\text { 3. Reduction of distance from Aralsk harbour to Aral } \\
\text { Sea was from } 75 \mathrm{~km}(2001) \text { to } 35 \mathrm{~km}(2010) \text {. } \\
\text { 4. The capacity of the Syr Darya river was increased } \\
\text { from } 300 \mathrm{~m}^{3} / \mathrm{sec} \text { (2001) to } 425 \mathrm{~m}^{3} / \mathrm{sec}(2017) \text {. } \\
\text { 5. Water loss into desert depressions has reduced } \\
\text { from } 5 \mathrm{BMC}(2003) \text { to } 0.2 \mathrm{BMC}(2009) \text {. }\end{array}$ \\
\hline
\end{tabular}

However, the population that strived in poverty now seeks fortunes through fishing. They even resort to illegal fishing during the fish breeding seasons (Chen, 2018; William, 2017). This could have severe long-term effects on the population growth of the fish. The controlled usage of resources is crucial for sustenance. This concept of sustained usage, therefore, applies to the restored lake. Immediately following the restoration phase is the sustaining phase which is highly resource-demanding. To sustain the restored NAS, an inflow of 6$8 \mathrm{~km}^{3}$ per year is required (FAO, 2012). Thus, water usage for agricultural practices must be monitored and kept under the necessary limit so that sufficient water can flow into the NAS. This limitation will hinder the growth of agricultural production and ultimately restrain the economic growth of the region. With migration made possible, the population might grow again, demanding more agricultural production. This vicious cycle needs to be broken. Investing in educating the population and supporting them to diversify the economy might bring about a change in the lifestyle and ultimately uplifting the economy.

\section{Discussion for South Aral Sea}

On the other hand, the government of Uzbekistan took a different approach towards the drying of SAS. They left the lake to its own fate. Instead of investing heavily in restoring the drying lake, the Uzbekistan government began tourism and extraction of minerals, oil and gas from the exposed 
lakebed. Oil, being one of the prominent products in demand, has promising effects on the country's economy and employment opportunities. However, economic growth will be a short-term success if the environmental conditions are bad for survival. Dust storms, which are the primary cause for the spreading of pollutants causing diseases must be taken care of. A considerable effort has been made towards the development of afforestation on parts of the dry bottom of SAS. The "Stabilization of the desiccated Aral Sea bottom in Central Asia," (Micklin, 2014) is a program that has been sponsored and monitored by the German government GTZ in collaboration with Uzbekistan's Forestry Research Institute. The aim of this project was to plant drought-resistant saplings, mainly saxaul-Haloxylon aphyllum to help stabilize the soil. According to the reports, by 2010 and $2015,2,000 \mathrm{~km}^{2}$ to $5,000 \mathrm{~km}^{2}$ of selfsustaining forest were noticed on the dried lakebed. The increase in plant population is believed to reduce the dust storms. However, reduction in dust storms did not bring about remarkable changes in the health conditions of the residing population (Living Asia, 2016; Micklin, 2014). 


\section{Chapter 5: Discussion}

\section{Health}

Several studies were conducted to find the correlation between the declining water level in the Aral Sea and the deteriorating health condition of the population living around the Aral Sea. This report centres around the studies conducted on six of the major health conditions observed in the population around the Aral Sea. A majority of the studies conducted are observational studies and fail to provide a scientific rationale to explain the relationship between the drying lake and observed health effects around it. These studies also tend to be region-specific and cannot be applied to the general case of drying lakes. The Aral Sea's shrinking can be attributed to the negligent anthropogenic activities conducted in the Aral Sea Basin which added pollutants to the Aral Seabed. Heavy metals, Persistent Organic Pollutants (POP's), chemical fertilizers like DDT and PCB and other pollutants have been found in the food chain and in the bodies of the population living around the Aral Sea. These pollutants have been known to cause the diseases discussed. However, there is a high degree of variance in the statistics provided by the various health studies conducted in this region. Moreover, the official health records maintained by the government do not match with the data collected by the studies. The health statistics vary to a considerable degree based on the reference chosen. All these associated variabilities make it difficult to draw a strong conclusion about the adverse health effects of the drying lakes in general.

There is no clear conclusion that the drying Aral Sea and its associated dust storms are the prime reason for the deteriorating health conditions. However, the dust storms facilitated the cause of health issues by spreading the pollutants across the Aral Sea region. Thus, the pollutants seem to be the primary cause of these diseases and dust storms are not to blame. With the absence of pollutants, the dust storms could be harmless towards the surrounding population's health. Conducting scientific cohort studies as opposed to crosssectional would help identify the specific causes for the health issues around the Aral Sea and drying salt lakes in general.

\section{Government Actions}

Drying of a lake is a natural phenomenon and it takes thousands of years to shrink, however, due to the intervention of human activities, the process accelerates drastically. For example, a significant portion of Lake Urmia and the Aral Sea dried out in 30-50 years of time. The economic trends around the lake basins are highly dependent on the water and this results in the decline of 
the lake level for a short-term increase in the economy. For a longer-term plan, more investments have to be made to restore the lake and to maintain the occupation and in turn the economy of the region. Overall, the restoration process affects the economy of the country.

Thus, summarizing the three perspectives of restoration, the NAS restoration project was estimated to cost US \$86 million and the ULRP is expected to cost US $\$ 1.3$ billion. Such heavy economic investments can be made if there is a promise of enough returns. The study of the Great Salt Lake in Utah shows a promising investment return opportunity via ecotourism (Marden et al., 2014). If not restoration, the alternate strategy is to use dry lake beds for mineral, oil and gas extraction. The SAS in Uzbekistan is a prime example of such a situation. This could provide employment opportunity and a much-needed boost to the economy. It is a viable option if necessary precautions are taken by the government to decimate health hazards.

One problematic pattern that was observed during this study revolved around the fishing and agriculture centred economy of the Aral Sea region. The poverty-stricken population seeks to turn tables via excessive fishing and agriculture. These activities affect the sustainable process of the restored lakes. It would be beneficial if the government made investments in educating and training the population on alternate means of income, thus diversifying the economy. Providing the citizens with diverse job prospects will help to spread the population thus reducing the density of population around the lake region. The diverse economy provides the citizens and the country an opportunity to slacken the reliability on agriculture for sustenance. 


\section{Chapter 6: Conclusion}

Great salt lakes are massive reservoirs of saline water. These lakes undergo natural changes spanning over several millenniums. But recently, these lakes have been drying at an accelerated rate due to anthropogenic activities. The ever-growing population, the increasing demand for water and agriculture centred economy seems to be the customary combination for the desiccation of great salt lakes. The diversion of the tributaries for domestic, industrial and irrigation purposes results in the reduction of inflow to the salt lakes. The shrinking of the salt lakes is the consequence of such activities. The Aral Sea and Lake Urmia are examples of such a predicament. The drying salt lakes give rise to health and socio-economic conditions.

Dust storms hailing from the drying lake beds were speculated to cause health disorders among the population residing near the Aral Sea. However, from the studies conducted on the reported disabilities, no solid evidence was found to show an undeniable connection to the dust storms. On the other hand, perilous pollutants were inducted into the lake through agriculture and industrial waste disposal. These pollutants also play a prominent role in causing the observed diseases and the dust storms provide a medium for the spreading of these pollutants. Therefore, the actual cause of the health issues is the pollutants added through anthropogenic activities. Thus, one could conclude that the dust storms are a natural phenomenon and they have no significant effect on human health.

The government of Uzbekistan, Kazakhstan and Iran took contrasting approaches towards the identical problem of drying salt lakes. NAS was restored by Kazakhstan with the implementation of SYNAS project which aided in maintaining the lake's water level. The Iranian government is making consistent efforts to restore LU by means of water transfer activities, but the restoration process has failed to keep up with the expected results. The SAS under Uzbekistan government was not restored but rather used to diversify the economy by means of oil and mineral extraction from the dry lake beds.

Based on the assessment of three strategies it can be concluded that a restoration is a viable option when the sustenance of the restored lake can be promised. The restored lake would potentially get the deterioration of current conditions when the regional economy depends on the high level of water usage, irrespective of the high efforts spent for restoration. On the other hand, the restoration activities might not be needed if the local economy is diversified from high water-consuming activities to other sectors. 


\section{Reference}

Alnazarova, A.S., 2010. The main demographic indicators of the population of the Aral region. VI International scientific and practical conf. - Poland 31-34.

http://rep.ksu.kz/bitstream/handle/data/1788/\%D0\%91\%D0\%B8\%D0 $\% \mathrm{BE} \% \mathrm{D} 0 \% \mathrm{BB} \% \mathrm{D} 0 \% \mathrm{BE} \% \mathrm{D} 0 \% \mathrm{~B} 3 \% \mathrm{D} 0 \% \mathrm{~B} 8 \% \mathrm{D} 1 \% 8 \mathrm{~F} \% 2080-$ 86.pdf? sequence $=1 \&$ isAllowed $=\mathrm{y}$

Anon, 2005. A regional overview of wastewater management and reuse in the Eastern Mediterranean Region.

Aquapedia, 2015. Urmia Lake: The Need for Water Diplomacy.

Ataniyazova, O.A., 2003. Health and ecological consequences of the Aral Sea crisis. 3rd World Water Forum Reg. Coop. Shar. Water Resour. Cent. Asia Kyoto 18.

Ataniyazova, O.A., Baumann, R.A., Liem, A.K.D., Mukhopadhyay, U.A., Vogelaar, E.F., Boersma, E.R., 2001. Levels of certain metals, organochlorine pesticides and dioxins in cord blood, maternal blood, human milk and some commonly used nutrients in the surroundings of the Aral Sea (Karakalpakstan, Republic of Uzbekistan). Acta Paediatr. 90, 801-808. https://doi.org/10.1111/j.1651-2227.2001.tb02808.x

Aubakirova, K.D., Bazarbayeva, T.A., Asen, U., 2015. Ecological state of the water resources of the Republic of Kazakhstan. Ecological series 1, 3136. https://bulletin-ecology.kaznu.kz/index.php/1eco/article/view/676 Bennion, P., Hubbard, R., O'Hara, S., Wiggs, G., Wegerdt, J., Lewis, S., Small, I., van der Meer, J., Upshur, R., on behalf of the Medecins san Frontieres/Aral Sea Respiratory Dust and Disease project team, 2007. The impact of airborne dust on respiratory health in children living in the Aral Sea region. Int. J. Epidemiol. 36, 1103-1110. https://doi.org/10.1093/ije/dym195

Bersimbaev, R.I., Bulgakova, O., 2015. The health effects of radon and uranium on the population of Kazakhstan. Genes Environ. 37. https://doi.org/10.1186/s41021-015-0019-3

Bochkov, N.P., 2003. Ecological human genetics. Environ. Genet. 82, 16-21. https://cyberleninka.ru/article/n/ekologicheskaya-genetika-cheloveka

Boros, E., Kolpakova, M., 2018. A review of the defining chemical properties of soda lakes and pans: An assessment on a large geographic scale of Eurasian inland saline surface waters. PLOS ONE 13, e0202205. https://doi.org/10.1371/journal.pone.0202205

Breckle, S.W., Geldyeva, G.V., 2012. Dynamics of the Aral Sea in Geological and Historical Times. https://www.researchgate.net/publication/226480946_Dynamics_of_t he_Aral_Sea_in_Geological_and_Historical_Times 
CAWater, 2019. Aral Data. URL http://www.cawaterinfo.net/aral/data/morpho_e.htm (accessed 9.10.19).

Chen, D.-H., 2018. Once Written Off for Dead, the Aral Sea Is Now Full of Life. URLhttps://www.nationalgeographic.com/news/2018/03/northaral-sea-restoration-fish-kazakhstan/ (accessed 10.9.19).

Columbia, 2019. The Aral Sea Crisis. URL http://www.columbia.edu/ tmt2120/impacts $\% 20$ to $\% 20$ life $\% 20$ in $\% 20$ the\%20region.htm (accessed 10.16.19).

Crighton, E.J., Elliott, S.J., Meer, J. van der, Small, I., Upshur, R., 2003. Impacts of an environmental disaster on psychosocial health and wellbeing in Karakalpakstan. Soc. Sci. Med. 56, 551-567. https://doi.org/10.1016/S0277-9536(02)00054-0

Deocampo, D., F Jones, B., 2014. Geochemistry of Saline Lakes. ResearchGate.

URL https://www.researchgate.net/publication/263085798_Geochemistry_ of_Saline_Lakes (accessed 9.6.19).

Derogatis, L., Lipman, RS, Covi, L., 1973. SCL-90: an outpatient psychiatric rating scale--preliminary report.', Psychopharmacology Bulletin 9, 1328.

Diba, B.A., 2016. Transfer of the Caspian Sea Waters is a violation of the International Law.

FAO, 2012. AQUASTAT - FAO's Information System on Water and Agriculture.

URL

http://www.fao.org/nr/water/aquastat/basins/aralsea/index.stm (accessed 10.6.19).

Fazel, N., Berndtsson, R., Uvo, C.B., Madani, K., Kløve, B., 2018. Regionalization of precipitation characteristics in Iran's Lake Urmia basin. Theor. Appl. Climatol. 132, 363-373. https://doi.org/10.1007/s00704-017-2090-0

Financial Tribune, 2018. Caspian, Van Water Transfer to Urmia Scientifically Unfeasible. Tinanc. Trib. URL https://financialtribune.com/articles/environment/90613/caspian-vanwater-transfer-to-urmia-scientifically-unfeasible (accessed 10.9.19).

Ghashghaie, M., Nozari, H., 2018. Effect of dam construction on lake urmia: Time series analysis of water level via ARIMA. ResearchGate. URL https://www.researchgate.net/publication/330544387_Effect_of_dam _construction_on_lake_urmia_Time_series_analysis_of_water_level_ via_ARIMA (accessed 11.9.19).

Gordeev, S.A., Posokhov, S.I., Kovrov, G.V., Katenko, S.V., 2013. Psychophysiological features of panic and generalized anxiety disorder. J. Neurol. Psychiatry 113, 11-14. 
https://www.mediasphera.ru/issues/zhurnal-nevrologii-i-psikhiatriiim-s-s-korsakova/2013/5/031997-7298201352izna

Gorvett, Z., 2017. The deadly germ warfare island abandoned by the Soviets. URL http://www.bbc.com/future/story/20170926-the-deadly-germwarfare-island-abandoned-by-the-soviets (accessed 3.19.19).

Granit, J., Jägerskog, A., Löfgren, R., Bullock, A., de Gooijer, G., Pettigrew, S., Lindström, A., 2010. R egiona 1 Water Intelligence Report Central Asia 32.

Groffman, P.M., Baron, J.S., Blett, T. et al. Ecosystems (2006) 9(1). https://doi.org/10.1007/s10021-003-0142-z

Hargrave, M., 2019. What Does the Incidence Rate Measure? Investopedia. URL https://www.investopedia.com/terms/i/incidence-rate.asp (accessed 10.18.19).

Harriman, L., 2015. The Future of the Aral Sea Lies in Transboundary Cooperation. World Meteorol. Organ. URL https://public.wmo.int/en/resources/bulletin/future-of-aral-sea-liestransboundary-co\%E2\%80\%93operation (accessed 9.10.19).

Herbst, S., 2006. Water, sanitation, hygiene and diarrheal diseases in the Aral Sea area (Khorezm, Uzbekistan). URL http://microdata.worldbank.org/index.php/citations/3483 (accessed 3.21.19).

Heydari, N., Jabbari, H., 2012. Worldwide environmental threats to Salt Lakes. International Journal of Design \& Nature and Ecodynamics, 7(3), pp.292-299.https://doi.org/10.2495/DNE-V7-N3292-299

IFAS, 2011. Water resources of the Aral Sea Basin » Serving the People of Central Asia. URL http://ec-ifas.waterunites-ca.org/aral_basin/66-thearal-sea-basin.html (accessed 11.8.19).

Igissinov, N., Igissinov, S., Moore, M.A., Shaidarov, M., Tereshkevich, D., Bilyalova, Z., Igissinova, G., Nuralina, I., Kozhakhmetov, S., 2011. Trends of Prevalent Cancer Incidences in the Aral-Syr Darya Ecological Area of Kazakhstan 12, 5.

Islamov, B., n.d. Central Asian Population in Historical Perspectives. URL http://www.ier.hitu.ac.jp/COE/Japanese/Newsletter/No.14.english/Isla mov.htm (accessed 9.30.19).

Iznak, A.F., Iznak, E.V., Sorokin, S.A., 2011. Dynamics and communication of parameters of cognitive evoked potentials and sensorimotor reactions in the treatment of apathetic depression. Neurology and Psychiatry. 9, 52-57. https://www.mediasphera.ru/issues/zhurnalnevrologii-i-psikhiatrii-im-s-skorsakova/2011/9/downloads/ru/031997-72982011910 
Jayaraj, R., Megha, P., Sreedev, P., 2017. Organochlorine pesticides, their toxic effects on living organisms and their fate in the environment 9 , 90-100. https://doi.org/doi:10.1515/intox-2016-0012

Jellison, R., Williams, W.D., Timms, B., Alcocer, J., Aladin, N.V., 2008. Salt lakes: values, threats and future, in: Polunin, N.V.C. (Ed.), Aquatic Ecosystems. Cambridge University Press, Cambridge, pp. 94-110. https://doi.org/10.1017/CBO9780511751790.010

Jerome, P., 2015. Lake (limnic) ecosystems URL https://slideplayer.com/slide/4183578/ (accessed 9.10.19).

Kamchatnov, P.R., S.S., 2014. Cognitive reserve, cognitive impairment and the possibility of their medical correction. Neurology and Psychiatry 3, 87-91. https://medi.ru/info/11548/

Khatami, S., Berndtsson, R., 2013. Urmia Lake Watershed Restoration in Iran: Short- and Long-Term.

Kunii, O., Hashizume, M., Chiba, M., Sasaki, S., Shimoda, T., Caypil, W., Dauletbaev, D., 2003. Respiratory Symptoms and Pulmonary Function among School-Age Children in the Aral Sea Region. Arch. Environ. Health Int. J. 58, 676-682. https://doi.org/10.3200/AEOH.58.11.676682

Kuzmin, A.I., 2005. The course of lectures "Fundamentals of demography. https://es.b-ok2.org/book/520962/e7a5ab

Living Asia, 2016. The Sea Of Comparing. URL http://livingasia.online/aralsea/uz_kaz (accessed 10.9.19).

LUDB, 2019. The Center for Land Use Interpretation. URL http://clui.org/ludb/site/bristol-dry-lake (accessed 9.3.19).

Mamaev, V., I, W., 2002. Seas Around Eurpoe, Caspian Sea. European Environment Agency.

Mamyrbayev, A., Dyussembayeva, N., Ibrayeva, L., Satenova, Z., Tulyayeva, A., Kireyeva, N., Zholmukhamedova, D., Rybalkina, D., Yeleuov, G., Yeleuov, A., 2016. Features of Malignancy Prevalence among Children in the Aral Sea Region. Asian Pac. J. Cancer Prev. APJCP 17, 5217-5221. https://doi.org/10.22034/APJCP.2016.17.12.5217

Mansoor, M., 2011. Deficiency Analysis of Iranian Wastewater Treatment Plants and Proposals for Improvements.

Marden, B., Micklin, P., Wurtsbaugh, W., 2014. Three Papers Submitted 58.

Masnaveva, L.., Budarina, L.., Kudaeva, I.., 2012. The state of the general reactivity of the body of adolescents living in areas with different levels of air pollution. Hyg. Sanit. 49-50. https://cyberleninka.ru/article/n/sostoyanie-obschey-reaktivnosti-upodrostkov-prozhivayuschih-v-rayonah-s-razlichnymi-urovnyamizagryazneniya-atmosfernogo-vozduha 
Massoud, T., 2010. Wastewater Treatment and Reuse in Iran: Situation Analysis. Tehran: Environment and Water research centre.

Massoud, T., Ahmad, A., 2005. Integrated Approach to Water and Wastewater Management for Tehran, Iran.

Micklin, P., 2019. Introduction to the Aral Sea and Its Region - Semantic Scholar. URL https://www.semanticscholar.org/paper/Chapter-2Introduction-to-the-Aral-Sea-and-Its-

Micklin/6f997d35df4c09fff4ba85b2e5162150ba6d289f (accessed 11.7.19).

Micklin, P., 2014. Efforts to Revive the Aral Sea, in Micklin, P., Aladin, N.V., Plotnikov, The Aral Sea: The Devastation and Partial Rehabilitation of a Great Lake, Springer Earth System Sciences. Springer Berlin Heidelberg, Berlin, Heidelberg, pp. 361-380. https://doi.org/10.1007/978-3-642-02356-9_15

Micklin, P., Aladin, N.V., 2008. Reclaiming the Aral Sea. Sci. Am. 298, 6471.

New World Encyclopedia, 2017. Freshwater - New World Encyclopedia. URL https://www.newworldencyclopedia.org/entry/Freshwater (accessed 9.10.19).

Newton, J., 2018. Why are the world's lakes disappearing? URL http://www.dailymail.co.uk/travel/travel_news/article5254133/Whyworlds-lakes-disappearing.html (accessed 5.12.19).

Opp, C., Groll, M., Semenov, O., Vereshagina, N. and Khamzina, A., 2019. Impact of the Aral Sea Syndrome-the Aralkum as a Man-Made Dust Source. In E3S Web of Conferences (Vol. 99). EDP Sciences.

Peachey, E.J., n.d. The Aral Sea Basin Crisis And Sustainable Water Resource Management In Central Asia 20.

Pescod, M.B., 1992. Wastewater treatment and use in agriculture. Rome.

Pezzullo, P.C., Cox, R., 2017. Environmental Communication and the Public Sphere. SAGE Publications.

Rajabova, s, 2014. Azer News.

Reilly, J., 2001. Premature Menopause: A Multidisciplinary Approach Whurr. J. Health Psychol. 6, 606-608. https://doi.org/10.1177/135910530100600512.

RMBEL, 2019. Lake Eutrophication. RMBEL. URL https://www.rmbel.info/primer/lake-eutrophication/ (accessed 9.2.19).

Rsymendiev, A., 1991. Development and implementation of the medical and recreational program Radiology for the population of the Aral region: a report on research. alna, Almaty. http://www.nauka.kz/page.php?page_id=108\&lang=1\&page=263 
Sacred Land Film Project, 2003. Zuni Salt Lake - United States. Sacred Land. URL https://sacredland.org/zuni-salt-lake-united-states/ (accessed 9.6.19).

Sakiev, K., 2016. Integrated approaches in the management of the health of the population of the Area. Ministry of Health and Social Development of the Republic of Kazakhstan.

Sakiev, K.Z., Battakova, S.B., Amanbekov, W.., Miyanova, G.., Ponizov, D.A., Khasenova, A.R., Kisapov, Z., 2017. Methodological Aspects Of Assessing The Mental Health Of The Popular Area Population (p. Kyrgyz, Shalkar, Arys, Ulytau, Atasu). Occup. Health Med. Ecol. 6687.

Scheffers, A.M., Kelletat, D.H., 2016. Lakes of the World with Google Earth, Coastal Research Library. Springer International Publishing, Cham. https://doi.org/10.1007/978-3-319-29617-3

Scurlock, D., 1998. General Technical Report RMRS, page number 104. ed. The Station.

Society, N.G., 2011. lake. Natl. Geogr. Soc. URL http://www.nationalgeographic.org/encyclopedia/lake/ (accessed 9.3.19).

Tereshkevich, D.P., Igisinov, N.S., Sharbakov, A.Z., 2011. Estimation of the mortality of women of fertile age in the zone of ecological disaster Kyzylorda region. Young Scientist. 2, 198-200. https://moluch.ru/archive/28/

Today's Zaman, 2013. The Iran Project.

Turdybekova, Y.G., Kopobayeva, I.L., Kultanov, B.Z., 2017. Comparative Assessment of Women's Reproductive Health in the Areas Bordering With the Aral Sea Region. Open access Macedonian journal of medical sciences 5 , 261. https://www.ncbi.nlm.nih.gov/pmc/articles/PMC5420785/

ULRP, 2019a. Hydrological Data. ULRP. URL http://www.ulrp.ir/en/hydrological-data/ (accessed 11.17.19).

ULRP, 2019b. Urmia lake challenges, actions and the way forward.

ULRP, 2018. A breif report on Urmia Lake Restoration Programme.

ULRP, 2017. Integrated Programe for Sustainable Water Resources Management in Lake Urmia Basin.

ULRP, 2015a. Socio-economy assessment of Lake Urmia Basin Lake Urmia Restoration National Committee, Tehran, Iran.

ULRP, 2015b. Urmia Lake Restoration Program Brief Report and Projects Outline.

UNDP, 2010. Reducing Transboundary Degradation in the Kura-Aras Basin. UNEP, 2017. Lake Urmia: Signs of recovery. 
UNESCO, 2017. 2017 UN World Water Development Report, Wastewater: The Untapped Resource - World. ReliefWeb. URL https://reliefweb.int/report/world/2017-un-world-water-developmentreport-wastewater-untapped-resource (accessed 9.3.19).

United Nations, 2000. Environmental Performance Reviews: Kazakhstan: First Review, ECE Environmental Performance Reviews Series. UN. https://doi.org/10.18356/0bb911ae-en

Wæhler, T., Dietrichs, E., 2017. The vanishing Aral Sea: Health consequences of an environmental disaster. ResearchGate. URL https://www.researchgate.net/publication/320208401_The_vanishing_ Aral_Sea_Health_consequences_of_an_environmental_disaster (accessed 3.9.19).

Water Unites, 2019. From the Aral Sea to the Aralkum: The Aral Sea catastrophe - From the Glaciers to the Aral Sea - Water Unites. URL https://www.waterunites-ca.org/themes/19-infoboxes/31-from-thearal-sea-to-the-aralkum-the-aral-sea-catastrophe.html (accessed 10.17.19).

Wiggs, G.F.S., O'hara, S.L., Wegerdt, J., Van Der Meer, J., Small, I., Hubbard, R., 2003. The dynamics and characteristics of aeolian dust in dryland Central Asia: possible impacts on human exposure and respiratory health in the Aral Sea basin. Geographical Journal, 169(2), pp.142157.https://doi.org/10.1111/1475-4959.04976

William, W., 2017. Fish as Property on the Small Aral Sea, Kazakhstan.

WMO, 2017. Sand and Dust Storms. World Meteorol. Organ. URL https://public.wmo.int/en/our-mandate/focus-areas/environment/SDS (accessed 11.17.19).

WMO, 2014. The future of the Aral Sea lies in transboundary co-operation. UNEP Sioux Falls 63.

World Bank, 2011. Implementation Completion And Results Report Republic Of Kazakhstan For A Syr Darya Control And Northern Aral Sea Phase1 Project.

World Bank, 1998. Aral Sea Basin Program (Kazakhstan, Kyrgyz Republic, Tajikistan, Turkmenistan and Uzbekistan) Water and Environmental Management Project.

Wunsh, G., 2007. Mortality of the population: trends, methods of study, forecasts: a collection of articles. 11-43. http://www.demoscope.ru/weekly/2007/0311/analit02.php

Wurtsbaugh, W.A., Miller, C., Null, S.E., DeRose, R.J., Wilcock, P., Hahnenberger, M., Howe, F., Moore, J., 2017. Decline of the world's saline lakes. Nat. Geosci. 10, 816-821. https://doi.org/10.1038/ngeo3052 
Wurtsbaugh, W., Miller, C., Null, S., Wilcock, P., Hahnenberger, M., Howe, F., 2016. Impacts of Water Development on Great Salt Lake and the Wasatch Front.

Zohary, T., Ostrovsky, I., 2011. Ecological impacts of excessive water level fluctuations in stratified freshwater lakes. Inland Waters 1, 47-59. https://doi.org/10.5268/IW-1.1.406

Zotkina, N.V., Zhadnov, V.A., Yakovleva, N.V., 2013. Individual clinical, neurological and personal characteristics of the development of chronic forms of cerebrovascular diseases. Personality in a changing world: health, adaptation, development 1, 88-94. https://cyberleninka.ru/article/n/individualnye-klinikonevrologicheskie-i-lichnostnye-osobennosti-razvitiya-hronicheskihform-tserebrovaskulyarnyh-zabolevaniy 


\section{Appendix}

\section{Appendix A: Urmia Lake Restoration Project (ULRP) activities and related expenses}

1. Control and reduction of water consumption in the agricultural sector Cost: US \$226,236,000

2. Control and reduction in the withdrawal of surface and groundwater in Lake Urmia Basin

Cost: US \$16,206,000

a. Prevent unauthorized withdrawals from surface water - US $\$ 7,455,000$

b. Installation of smart meters to control water withdrawal from tributary rivers - $\underline{\mathrm{US} \$ 8,751,000}$

3. Initiatives on Protection and mitigation of negative impacts

Cost: US $\$ 22,201,000$

a. Identification and stabilization of dust sources - $\underline{\text { US }}$ $\$ 17,534,000$

b. Study and implementation of Lake Urmia National Park - US $\$ 3,333,000$

c. Preparation and implementation of programmes to prevent and reduce health, environment and social issues arising from drying lake - US $\$ 667,000$

d. Diversifying Economy - US $\$ 667,000$

4. Studies and software measures

Cost: US $\$ 25,635,000$

a. Development and implementation of a public awareness programme to communicate the importance of lake restoration - US $\$ 7,334,000$

b. Cadastral mapping of Lake Urmia Basin - US $\$ 8,000,000$

c. Impact study on the Kalantari causeway on Lake Urmia's ecosystem - US $\$ 333,000$

d. Feasibility assessment of Lake Urmia's salts for industrial application - US $\$ 1,333,000$

e. Study of the plans to transfer water to the Lake Urmia from the Caspian Sea - US $\$ 467,000$

f. Monitoring and evaluating implemented projects - US $\underline{\$ 6,835,000}$ 
g. Design and deployment of decision support system - $\underline{\mathrm{US}}$ $\$ 667,000$

h. Study to reduce evaporation and perform cloud seeding within Lake Urmia Basin- US \$666,000

5. Facilitate and increase of the water volume entering the Lake throughout structural measures

Cost: US $\$ 23,535,000$

a. Water transfer to Lake Urmia's islands and wetlands through Hasanloo Dam - US \$667,000

b. Water transfer through Rivers - US $\$ 22,868,000$

6. Water supply from new water resources

Cost: US $\$ 312,779,000$

a. Water transfer from Zab River to Lake Urmia - US $\$ 197,099,000$

b. Water transfer from wastewater treatment plants - $\underline{\mathrm{US}}$ $\$ 114,347,000$

c. Research and implementation of water transfer from the Aras River - US \$1,333,000 


\section{Appendix B: Syr-Darya Control and Northern Aral Sea Project (SYNAS) activities and related expenses}

7. Recuperation of Northern Aral Sea- US \$23.19 million

8. Improvement of Hydraulic regulators for the Syr Darya- US \$40.95 million

9. Rehabilitation of the Chardara Dam- US \$14.10 million

10. Restoration of Aquatic resources and development of Fisheries- US \$2 million

11. Monitoring and Evaluation- US \$1.50 million

12. Project Management- $\underline{\text { US } \$ 1.60 \text { million }}$ 